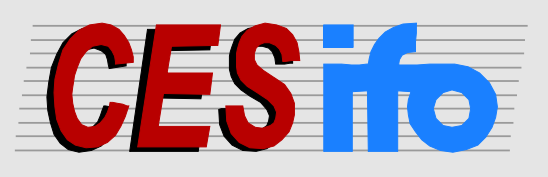

\title{
Working
}

Papers

www.cesifo.org/wp

\section{Private, Social and Self-Insurance for Long-Term Care in the Presence of Family Help A Political Economy Analysis}

\author{
Philippe De Donder \\ Pierre Pestieau
}

CESIFO WORKING PAPER NO. 4352

CATEGORY 3: SOCIAL PROTECTION

JULY 2013
An electronic version of the paper may be downloaded
- from the SSRN website: Www.SSRN.com
- from the RePEc website: Www.RePEc.org
- from the CESifo website: www.CESifo-group.org/wp

\section{CESifo}




\title{
Private, Social and Self-Insurance for Long-Term Care in the Presence of Family Help A Political Economy Analysis
}

\begin{abstract}
We study the political determination of the level of social long-term care insurance when voters also choose private insurance and saving amounts. Agents differ in income, probability of becoming dependent and of receiving family help. Social insurance redistributes across income and risk levels, while private insurance is actuarially fair. The income-to-risk ratio of agents determines whether they prefer social or private insurance. Family support crowds out the demand for both social and, especially, private insurance, as strong prospects of family help drive the demand for private insurance to zero. The availability of private insurance decreases the demand for social insurance but need not decrease its majority chosen level.
\end{abstract}

JEL-Code: D720, I130, J140.

Keywords: long-term care, social insurance, familism, crowding out, weak and strong prospects of family help, voting.

\author{
Philippe De Donder* \\ Toulouse School of Economics \\ Manufacture des Tabacs \\ MS102, 21 allée de Brienne \\ France-31015 Toulouse Cedex 6 \\ philippe.dedonder@tse-fr.eu
}

\author{
Pierre Pestieau \\ CREPP, HEC-Management School \\ University of Liège \\ Boulevard du Rectorat, 7 (B 31) \\ Belgium - 4000 Liège \\ p.pestieau@ulg.ac.be
}

\footnotetext{
* corresponding author
}

July 25, 2013

A former version of this paper has been presented under the title "Voting over LTC public insurance" in Munich (CESifo area conference on public sector economics), Toulouse and Nashville (Vanderbilt University conference on tax theory). We thank participants as well as Helmuth Cremer, Katherine Cuff and Erik Schokkaert for their comments. Financial support from the Chaire "Marché des risques et création de valeur" of the FdR/SCOR is gratefully acknowledged. 


\section{Introduction}

While health care services aim at changing a health condition (from unwell to well), long-term care (hereafter LTC) merely aims at making the current condition (unwell) more bearable. Individuals need LTC due to disability, chronic condition, trauma, or illness, which limit their ability to carry out basic self-care or personal tasks that must be performed every day. Such activities are defined as activities of daily living (eating, dressing, bathing, getting in and out of bed, toileting and continence) or instrumental activities of daily living (preparing own meals, cleaning, laundry, taking medication, getting to places beyond walking distance, shopping, managing money affairs and using the telephone/Internet). A person is dependent if he or she has limitations in either type.

Dependent people can draw on four different types of resources to help alleviate their daily living problems. By far the most important quantitatively are their own resources (self-insurance ${ }^{1}$, or savings) and family help (mainly through informal help). Several countries also offer some form of social LTC insurance, although the size of these programs is usually low, especially compared to the pension programs. Finally, except for a handful of countries (such as the US and France), private insurance's role is negligible, and in any case consistently smaller than that of the State.

Several articles have studied the interactions between some of these resources (see the literature section hereunder). The value added by our paper is that it considers simultaneously the four types of resources (family help, private, social and self-insurance) and that it studies the political choice of the level of social LTC insurance. More precisely, we study the determinants of the individual demand (and political support) for social, private and self-insurance in an environment where people differ in income, risk and availability of family help. As stated above, the availability of family help is of first importance for LTC, and distinguishes our approach from the literature studying the political support for other kinds of social insurance programs, such as health or social security. ${ }^{2}$

We develop a framework where agents live two periods. They earn an income, pay taxes, save and buy private LTC insurance when young. Beyond income, they also differ in the probability of becoming dependent when old, and in the probability of receiving help from their family if dependent. They choose by majority voting the value of the proportional income tax rate that finances the

\footnotetext{
${ }^{1}$ As other papers dealing with LTC (see Costa-Font 2010 for instance), we use the general definition of self-insurance (assets set aside to cover possible losses) rather than the more specific meaning used in insurance theory (prevention activities reducing the severity of the potential loss).

${ }^{2}$ For instance, over $80 \%$ of dependent elderly live in their home or with their children, and for these people most of the care is informal. See Stone (2000).
} 
lump sum social insurance transfer received if dependent. A crucial assumption is that social LTC insurance redistributes across income and (ex ante) across risk, while private insurance is actuarially fair and not redistributive. To level the playing field, both forms of insurance are equally efficient (no loading factor, no cost of public fund or distortionary impact from taxation).

While the endogenize the levels of the three types of insurance, family help is modelled as an exogenous norm. This corresponds to what Costa-Font (2010) calls familism, a short hand for "familism culture", or "the embeddedness in a family's social norms (family ties)" (p 2). Familism is exogenous because "need of LTC is a non-repeated experience in human life, and that individuals are arguably prone to make decisions on the basis of intergenerational cultural values rather than repeatedly experienced actions. More specifically, parents tend to transfer their values to their children (...), which includes cultural norms towards funding and providing care in old age." (p 3). For simplicity, we do not model the distinction between formal and informal help.

We first study the individually most-preferred (self, private and social) insurance allocation of agents. We show that agents most-prefer either social or private insurance, depending of their income-to-risk ratio. Whatever this ratio, the support for their most-preferred insurance form decreases with the probability of receiving family help. This is in line with the empirical results obtained by Costa-Font (2010). We then introduce the distinction between weak and strong prospect of family help: prospects are strong (resp., weak) for a given individual if her expected marginal utility is lower (resp., higher) when she is dependent with family as the only source of help (i.e., without any private or social insurance handouts) than when she remains autonomous. Social insurance happens to be more resilient than private insurance to family help, in the sense that no one with strong prospects of family help most prefers any private insurance, while some of these agents may still prefer a positive amount of social insurance. The main driving force of this result is that strong prospects of family help cancel out any need for an actuarially fair insurance like private insurance, while the (income and risk) redistribution embedded into social insurance induces a positive support from low income-to-risk agents. The larger support for social insurance when prospects of family help are strong is in line with the stylized fact mentioned in the introduction that social LTC insurance is more widespread worldwide and larger than private insurance in the countries where they coexist (although both are of a small size, which can be explained by our model as due to sizeable family help). Our model also generates a novel testable implication regarding the amount of self-insurance, which is not monotone in family help: it first increases with family help (as agents substitute more saving to less insurance) but then decreases with family help when agents prefer self-insurance to any other form of insurance. 
We then show that there exists a Condorcet winning level of social LTC insurance (i.e., a level preferred by a majority of voters to any other level) even though voters differ in three dimensions. Voters' characteristics conducive to a positive majority chosen level of social insurance are the existence of a large fraction of agents with low income-to-risk ratios (so that the correlation between income and risk does matter), and with weak prospects of family help. We finally study how the availability of private insurance impacts the support for social LTC insurance. This question is of interest as countries such as France are currently considering how to facilitate the access to private LTC insurance. Moreover, as explained below the literature has concentrated on the opposite relationship, namely the impact of social on private insurance. We obtain that, even though both types of insurance are substitutes, so that introducing private insurance decreases the support for social insurance by some agents, the majority chosen level of social insurance need not decrease. The intuition for this result is that only agents with large income-to-risk ratios switch their preference from social to private insurance when the latter is made available, and these agents may constitute a minority. This will always be the case if agents do not differ in risk, because of the positive skewness of the income distribution.

\section{$1.1 \quad$ Literature}

As mentioned above, a rich literature has studied the interactions between private, social and self-insurance together with family help in the context of LTC. To the best of our knowledge, no paper takes the four forms of resources into account simultaneously.

Both Meier (1996) and Faber (1996) develop a two-period overlapping generations model where young individuals save and choose how much private LTC insurance to buy. They study how these two decisions are affected by various institutional settings, such as pure private funding, social aid (where the public sector pays the part of the cost of LTC that an individual cannot afford), mandatory social insurance (funded or pay-as-you go) or obligatory minimum level of private coverage. Their focus is on aggregate saving and private insurance by a cohort, and they abstract both from family help and from the determination of the type/size of public policy. They often obtain ambiguous results as to the impact of the public policy on saving or private insurance.

Pauly (1990) studies various reasons why informed and risk averse agents do not buy actuarially fair private LTC insurance. His main argument is that Medicaid crowds out the demand for private insurance, because it reimburses all LTC costs (up to a threshold) once private funding is exhausted. Empirical evidence does not appear to confirm this phenomenon (Norton, 1995; Brown and Finkelstein, 2007). Pauly (1990) also investigates the interactions between family help 
and private insurance. He shows that the concerns for not impoverishing one's spouse and for leaving a bequest do not always generate a positive demand for private LTC insurance. He also studies the manipulation of bequests in order to incentivize children to provide informal help. His seminal approach has given rise to several analytical analysis of this so-called "intra-family moral hazard problem", by Courbage and Zweifel (2011) and Zweifel and Strüwe $(1996,1998)$ among others. There seems to be little empirical support for intra-family moral hazard: Sloan and Norton (1997) find that the bequest motive does not influence the demand for private insurance in the US, while Mellor (2001) finds no evidence consistent with the idea that the availability of caregivers discourages parents from obtaining market-purchased LTC insurance. Courbage and Roudaut (2008) rather find support in French data for an altruistic motive since LTC insurance is purchased not only to preserve bequests and to financially protect families in the event of disability, but also to reduce the burden of potential informal care givers.

All these papers either abstract from social insurance or take its characteristics as exogenous. There is surprisingly little literature on the determination of the (socially or individually) optimal level of social LTC insurance, especially when compared with the related issues of health care, social security and annuities. ${ }^{3}$ On the normative side, Cremer and Pestieau (2011) use a model close to the one of this paper; they show that the case for social LTC insurance can only be defended when tax redistribution is restricted. On the positive side, Nuscheler and Roeder (2013) study how the heterogeneity in individual income and risk affects the preferences for redistributive income taxation versus public financing of LTC. Their model allows LTC to be provided by informal help received from the family, or through family transfers in cash and government's transfers. Insurance (whether social, private or self-insurance in the form of saving) is not available since voters know whether the elderly in the family is dependent or not when taking their decisions. There is also no room for the correlation between income and risk, since the proportion of dependent elderly is the same in the two income classes considered. Their main result is the prediction of a negative correlation between income inequality and public LTC spending. De Donder and Leroux (2013) stress the behavioral biases exhibited by agents who vote for social LTC insurance and buy LTC annuities, a financial product that serves a higher transfer if dependent than if not. Agents all have the same income and risk (there is no family help) and differ in both the type and degree of myopia. They obtain that the low demand for private insurance is better explained by underestimation of the risk of becoming dependent than by procrastination.

The paper is organized as follows. Section 2 presents the model. Section 3 describes the most-preferred social, private and self-insurance allocation of agents.

\footnotetext{
${ }^{3}$ The economic literature on various other aspects of LTC is surveyed in Cremer et al. (2009).
} 
Section 4 studies the majority-chosen value of the social insurance contribution rate. Section 5 concludes.

\section{The Model}

We consider a continuum of individuals living two periods. When young, they earn a wage, pay income taxes, save and buy private LTC insurance. When old, they live out of their saving, plus the social and private insurance transfers if they need LTC, plus a transfer from the family if they have caring children and they need LTC. There are three sources of heterogeneity among individuals $i$ : their exogenous income, denoted by $w_{i}>0$, their probability of needing LTC $\left(\pi_{i} \in\right] 0,1[)$ and their probability of having (caring and close) ${ }^{4}$ children when needing LTC $\left(p_{i} \in\right] 0,1[)$. An agent of type $i$ is thus characterized by the triplet $\left(w_{i}, \pi_{i}, p_{i}\right)$.

A young individual $i$ 's lifetime utility function is given by

$$
U_{i}=u\left(c_{i}\right)+\left(1-\pi_{i}\right) u\left(s_{i}\right)+\pi_{i}\left[p_{i} H\left(d_{i}^{c}\right)+\left(1-p_{i}\right) H\left(d_{i}^{n}\right)\right] .
$$

The first term of (1) measures the instantaneous utility of individual $i$ when young, while the last two terms record his utility when old (for simplicity, we assume away any discounting of future utility). First-period consumption is denoted by

$$
c_{i}=w_{i}(1-\tau)-s_{i}-a_{i}
$$

where the first term measures disposable income when young, with $\tau$ a (proportional) contribution rate on labor income. The second term $s_{i}$ is private saving, while $a_{i}$ denotes the amount of private LTC insurance bought. ${ }^{5}$

In the second period of life, we distinguish the utility function when autonomous (with probability $1-\pi_{i}$ ), denoted by $u($.$) , from the utility when needing$ LTC (with probability $\pi_{i}$ ), denoted by $H($.$) . Agents have the same instantaneous$ utility function $u($.$) when young and when old but autonomous. Both u($.$) and$

\footnotetext{
${ }^{4}$ There are many reasons why some parents cannot count on any assistance from their offspring: (i) they do not have children or their children prematurely died; (ii) their children are not altruistic; (iii) they migrated far away from each other; (iv) parents and children do not get along.

${ }^{5}$ We do not model the transfer made by some young agents to their dependent parents in the first period of their life. This is consistent with the assumption that LTC transfers are tax deductible, or that they take the form of informal help that has as opportunity cost foregone income on the labor market. In both these cases, the income $w_{i}$ is income net of LTC transfers to parents. Introducing explicitly the LTC transfer to parents would add a fourth (and binary) dimension of heterogeneity to our already complex model. Moreover, the role played by this transfer would be very similar to the one played by income, so we would gain very little additional insight.
} 
$H($.$) are increasing and concave functions of consumption. We assume that both$ satisfy the condition of infinite marginal utility for zero consumption levels. We also assume that $u(c)>H(c)$ for any consumption level $c$, but that $u^{\prime}(c)<H^{\prime}(c)$ for all $c$ : people are happier if not in need of LTC, but have a higher marginal utility if dependent. Note that $H($.$) can be viewed as a reduced form of a utility$ comprising both standard consumption and LTC spending. The assumption that $u^{\prime}(c)<H^{\prime}(c)$ is satisfied by definition if the advent of dependency is associated exclusively with financial costs $z$, in which case $H(c)=u(c-z)$. If dependency is also characterized by a change in preferences, we enter the realm of state-dependent utility functions. The assumption that $u^{\prime}(c)<H^{\prime}(c)$ may then be disputed (see, for instance, Finkelstein et al. 2009, 2013), since some goods may substitute or complement good health. Since our focus is on the financial cost of dependency, this assumption remains reasonable up to a certain consumption level, and we implicitly assume in this paper that this consumption threshold is not reached. Finally, observe that if dependent people do not have higher marginal utility than when autonomous, then the lack of demand for (social and private) LTC insurance is not puzzling at all.

With probability $1-\pi_{i}$, the individual remains autonomous and enjoys his saving (without loss of generality we posit a zero interest rate on savings). If the individual becomes dependent (with probability $\pi_{i}$ ), his consumption level depends on whether he receives help from his family. He does not receive such help with probability $1-p_{i}$, in which case his consumption level is given by

$$
d_{i}^{n}=s_{i}+b+x_{i},
$$

where $b$ denotes the social insurance transfer, and $x_{i}$ the private insurance transfer. With probability $p_{i}$, the dependent individual receives a transfer $f$ from his family. As explained in the introduction when discussing familism, we assume that $f$ is exogenously set by a social norm. We do not model the distinction between formal and informal help, but rather measure $f$ as the monetary value of all the help received from the family. Consumption in that case is given by ${ }^{6}$

$$
d_{i}^{c}=s_{i}+b+f+x_{i} .
$$

The social insurance lump sum transfer $b$ paid to all dependent agents is financed by the proportional tax $\tau$ on first-period labor income. For simplicity, we assume away demographic (and economic) growth, so that the social insurance program's budget constraint is given by

$$
b=\tau \frac{\bar{w}}{\bar{\pi}},
$$

\footnotetext{
${ }^{6}$ We do not model intra-family moral hazard, both for simplicity and because there is little empirical support for this phenomenon (see the literature section in the introduction).
} 
where $\bar{w}$ is the average income and $\bar{\pi}$ is the average probability of needing LTC (and thus, by the law or large numbers, the proportion of old individuals who become dependent).

We model the private insurance scheme as actuarially fair: the premium does not depend on income but is based on the individual risk $\pi_{i}$ (which is assumed to be observable by the insurer). Since LTC need is binary, there is no place for ex post moral hazard. Also, we assume that insurers do not condition the payment on the transfer made by children (for instance because they cannot observe it). Individuals can choose the quantity of private insurance that they buy, as measured by the insurance premium $a_{i}$ paid in the first period of life. In case they need LTC, they then receive an actuarially fair amount

$$
x_{i}=\frac{a_{i}}{\pi_{i}}
$$

The timing of the model runs as follows. Individuals first choose the value of $\tau$ by majority voting. We assume that only young agents vote ${ }^{7}$ and that they vote as if the result of the vote would continue to hold in the next period. ${ }^{8}$ They then observe the result of the vote, and decide privately how much to save and to privately insure against the risk of dependency. No decision is taken in the second period of life.

\section{Most-preferred public, private and self-insurance allocation}

We look for the most-preferred amounts of social, private and self insurance (respectively denoted by $\tau_{i}^{*}, a_{i}^{*}$ and $s_{i}^{*}$ ) of agents differing in income $w_{i}$, risk $\pi_{i}$ and family help $p_{i}$. The respective first-order conditions (FOCs) $\operatorname{are}^{9}$

$$
\begin{array}{ll}
F O C \tau_{i} & : \bar{w} \frac{\pi_{i}}{\bar{\pi}}\left[-\frac{w_{i}}{\pi_{i}} \frac{\bar{\pi}}{\bar{w}} u^{\prime}\left(c_{i}\right)+E H_{i}^{\prime}\right] \leq 0, \\
F O C a_{i}: & -u^{\prime}\left(c_{i}\right)+E H_{i}^{\prime} \leq 0 \\
F O C s_{i}: & -u^{\prime}\left(c_{i}\right)+\left(1-\pi_{i}\right) u^{\prime}\left(s_{i}\right)+\pi_{i} E H_{i}^{\prime}=0,
\end{array}
$$

\footnotetext{
${ }^{7}$ In the absence of altruism, old agents are in favor of the value of $\tau$ which maximizes the transfer $b$ if they need LTC (or if they do not know yet whether they will be dependent later), and are indifferent as to the value of $\tau$ if not dependent. Their preference over $\tau$ thus does not depend on their $\left(w_{i}, p_{i}, \pi_{i}\right)$ characteristics, but simply on their dependency status. Allowing old people to vote would then complexify the analysis without bringing any novel insight.

${ }^{8}$ This assumption is standard in the positive literature on pensions. See for instance Casamatta et al. (2000)

${ }^{9}$ The fact that decisions are taken sequentially (first $\tau$ and then $a$ and $s$ ) does not matter in this section since we look at the most-preferred allocation of individual $i$.
} 
where

$$
E H_{i}^{\prime}=p_{i} H^{\prime}\left(s_{i}+b+\frac{a_{i}}{\pi_{i}}+f\right)+\left(1-p_{i}\right) H^{\prime}\left(s_{i}+b+\frac{a_{i}}{\pi_{i}}\right)
$$

is the expected marginal utility in case of LTC of an agent of type $i$. Observe that the formulation of the FOC for saving holds with equality thanks to the assumption that $\lim _{c \rightarrow 0} u^{\prime}(c)=\infty$ (i.e., everyone saves a positive amount at his optimum).

The following definition will prove helpful throughout the paper.

Definition 1 : The prospect of family help of agent $i$ is weak if

$$
\left(1-p_{i}\right) H^{\prime}(x)+p_{i} H^{\prime}(x+f)>u^{\prime}(x),
$$

and is strong otherwise. ${ }^{10}$

Family help may be weak either because the transfer $f$ is low or because the probability $p_{i}$ to receive it is low. More precisely, a sufficient (although not necessary) condition for a weak family help prospect is that $H^{\prime}(x+f)>u^{\prime}(x)$. If we assume that $H(x)=u(x-z)$, this means that $f<z$ : if dependency is modelled as the equivalent of a monetary loss $z$, then the prospect of family help is weak for all agents if the amount of help from the family, $f$, is lower than the damage $z$. If $f>z$, the prospect of family help may be weak for individuals who have a low probability $p_{i}$ of receiving it.

We obtain the following proposition.

Proposition 1 (i) Agents never most-prefer at the same time positive amounts of social and private insurance (i.e., $\left(\tau_{i}^{*}>0, a_{i}^{*}>0\right)$ is impossible), except if $w_{i} / \pi_{i}=\bar{w} / \bar{\pi}$ in which case agent $i$ is indifferent between the two forms of insurance, provided that they add to her most-preferred total insurance level.

(ii) Individuals with a weak prospect of family help prefer some social but no private insurance (i.e., $\tau_{i}^{*}>0, a_{i}^{*}=0$ ) if $w_{i} / \pi_{i}<\bar{w} / \bar{\pi}$, and some private but no social insurance (i.e., $\tau_{i}^{*}=0, a_{i}^{*}>0$ ) if $w_{i} / \pi_{i}>\bar{w} / \bar{\pi}$.

(iii) No individual with a strong prospect of family help prefers private insurance $\left(a_{i}^{*}=0\right.$ for all $\left.i\right)$. Also, such agents prefer some social insurance (i.e., $\tau_{i}^{*}>0$ ) if $w_{i} / \pi_{i}<(\bar{w} / \bar{\pi}) E H_{i}^{\prime} / u^{\prime}\left(c_{i}\right)<\bar{w} / \bar{\pi}$, and no social insurance at all (i.e., $\tau_{i}^{*}=0$ ) otherwise.

\footnotetext{
${ }^{10}$ We will assume for simplicity that the inequality has the same sign for all values of $0<$ $x<w_{i}$. Although it need not be the case for all functions $H($.$) and u($.$) , it is of course true if$ $H(x)=u(x-z)$. Also, we take the functions $H($.$) and u($.$) (and their curvature) as given and$ concentrate on how family help affects the comparison of expected marginal utilities.
} 


\section{Proof: See Appendix}

The intuition for this proposition runs as follows. Comparing the FOCs for social and private insurance $((3)$ and (4)), one immediately sees that agents prefer to use social insurance if $w_{i} / \pi_{i}<\bar{w} / \bar{\pi}$, and private insurance otherwise. The intuition for this result is that social insurance redistributes across income and (ex ante) across risk levels, because the social insurance premium increases with individual income while the LTC transfer does not, and because neither the social premium nor the transfer are conditioned on the individual risk. At the same time, private insurance is actuarially fair and does not redistribute across income levels. Agents with a low income-to-risk ratio then prefer social to private insurance, while agents with a large ratio prefer private to social insurance. Observe that the threshold $\bar{w} / \bar{\pi}$ is independent (i) of family help both at the individual $\left(p_{i}\right)$ and social $(f)$ levels, and (ii) of the correlation between income and risk in society (i.e., it is the ratio of average income to average risk, rather than the average ratio of income-to-risk, that matters). The latter observation comes from the fact that social insurance serves a lump sum transfer to dependent agents, with the transfer increasing in the tax base (as measured by average income) and decreasing in the proportion of recipients (which, by the law of large numbers, equals the average risk of becoming dependent).

Proposition 1 also shows that everyone with a weak prospect of family help most-prefers a positive amount of some form of insurance. Agents with a strong prospect of family help have no need for any actuarially fair and non-redistributive insurance, since their expected marginal utility if dependent is smaller than if autonomous in the absence of insurance transfers. Such agents then do not buy any private insurance $\left(a_{i}^{*}=0\right)$, but they favor a positive social insurance level if their income-to-risk ratio is small enough, compared to the ratio of average income to average risk, that they benefit a lot from the (risk or income) redistribution embedded in the social insurance program. Observe that the threshold income-torisk ratio below which $\tau_{i}^{*}$ is positive depends on family help characteristics, since it decreases with both $p_{i}$ and $f$. As the prospect of family help increases, agents need to benefit more from the redistributiveness of social insurance (thanks to a low income-to-risk ratio) to favor a positive value of $\tau$.

We can then summarize the impact, at the extensive margin, of family help on the preferences for social and private insurance. If the transfer $f$ is low enough that the prospect for family help is weak for all agents, then family help has no impact on whether agents prefer a positive amount of social or of private insurance. If $f$ is large enough that the family help prospects are strong for at least some agents (with large values of $p_{i}$ ), then family help totally crowds out support for private insurance among these agents, and also totally crowds out the support for social insurance for these agents whose ratio of income to risk is slightly lower than the 
ratio of average income to average risk.

In order to complete this picture of the crowding out effects of family help on the support for insurance, we now proceed to the comparative static analysis of the most-preferred amount of insurance and of saving. We first study the group of agents who most-prefer a positive amount of social insurance.

We introduce the following assumption.

Assumption 1 The coefficient of relative risk aversion $R\left(c_{i}\right)=-c_{i} u^{\prime \prime}\left(c_{i}\right) / u^{\prime}\left(c_{i}\right)$ is low:

$$
\begin{aligned}
& u^{\prime}\left(c_{i}\right)+w_{i} u^{\prime \prime}\left(c_{i}\right)>0 \\
\Leftrightarrow & R\left(c_{i}\right)<\frac{c_{i}}{w_{i}}<1 .
\end{aligned}
$$

Note that this assumption is slightly stronger than the assumption that $R\left(c_{i}\right)<$ 1 since $w_{i}>c_{i}{ }^{11}$ As we will see shortly, this assumption is used only as a sufficient (although not necessary) condition to ensure that the derivative of the mostpreferred social insurance contribution rate with respect to income is negative.

Proposition 2 Take the individuals with $a_{i}^{*}=0$ while $\tau_{i}^{*}>0$ (and $s_{i}^{*}>0$ ). We obtain that

(i) a larger income $w_{i}$ increases $s_{i}^{*}$ and decreases $\tau_{i}^{*}$, under Assumption 1;

(ii) a larger family help (either $p_{i}$ or $f$ ) increases $s_{i}^{*}$ and decreases $\tau_{i}^{*}$;

(iii) a larger risk $\pi_{i}$ decreases $s_{i}^{*}$ and increases $\tau_{i}^{*}$.

Proof: Repeated use of Cramer's rule - see Appendix.

Before giving the intuition for these results, it is worth emphasizing that, although the ratio $w_{i} / \pi_{i}$ determines whether agent $i$ prefers social to private insurance, it does not determine the value of $\tau^{*}$ by itself. For instance, two agents with the same value of the ratio will typically prefer different values of $\tau^{*}$ if they differ in $w, \pi$ or $p$.

To understand the intuition behind Proposition 2, observe first that saving and social insurance are (imperfect) substitutes (since they constitute two technologies to move resources from the present into the future), so that increasing one exogenously decreases the most-preferred level of the other, ceteris paribus.

\footnotetext{
${ }^{11}$ In a recent paper studying the LTC insurance market, Karagyozova and P. Siegelman (2012) surveys the empirical literature on relative risk aversion. They report very large ranges for empirically plausible individual values of $R$ : from $[0.35,1]$ for Hansen and Singleton (1993) to $[0.029,680]$ for Halek and Eisenhauer (2001). Holt and Laury (2002) estimates that two thirds of respondents in their study have a value of $R$ between 0.15 and 0.93 . Assumption 1 then seems reasonable.
} 
Then, each individual characteristic (income, family or risk) impacts a decision $\left(\tau_{i}^{*}\right.$ or $\left.s_{i}^{*}\right)$ directly, but also indirectly through its impact on the other decision.

We start with the impact of income, noting that $w_{i}$ plays a role only in the first period of life, since no transfer is conditioned on income when old. An increase in individual income has two direct effects on $\tau_{i}^{*}$ : it makes social insurance more expensive (by increasing the tax payment), but it also decreases the marginal utility of first-period consumption (and thus the marginal utility cost of the social insurance transfer). If marginal utility does not decrease too fast (i.e., if Assumption 1 holds), the first impact is larger than the second and the net direct effect of an increase in income is to decrease $\tau_{i}^{*}$. The only direct impact of a larger income on the saving decision is the lower marginal utility from first-period consumption, which increases the optimal saving amount $s_{i}^{*}$. We then have that the direct and indirect effects of an increase in income reinforce themselves: a larger income decreases $\tau_{i}^{*}$ directly but also indirectly because it makes saving more attractive. Likewise, a larger income increases saving directly but also indirectly by discouraging social insurance.

The impact of family help (measured by either $p_{i}$ or $f$ ) runs as follows. Increasing family help decreases the expected marginal utility in case of dependency (because of a larger consumption level when help is received if $f$ increases, and because of a larger weight on the state of the world where help is received, and thus marginal utility lower, if $p_{i}$ increases). This exerts a negative direct impact on both $\tau_{i}^{*}$ and $s_{i}^{*}$, since ceteris paribus it decreases the marginal utility benefit from transferring income into the future in both cases. On the other hand, indirect effects have the opposite sign: the decrease in incentives to save tend to increase the incentive to favor social insurance, while the decrease in incentives to insure tends to increase the incentive to save. We obtain that the direct effect is larger than the indirect for social insurance, while the opposite occurs for saving. Intuitively, increases in $p_{i}$ or $f$ weaken the expected marginal utility if dependent, and thus decrease the desire to insure as measured by $\tau_{i}^{*}$. This in turn decreases the marginal utility from first-period consumption, and pushes the individual to save more. In other words, more family help decreases the expected marginal utility when dependent compared to being non dependent, and leads the individual to reallocate his portfolio in favor of saving and against social insurance.

A larger individual risk $\pi_{i}$ directly increases $\tau_{i}^{*}$ since it raises the probability to receive the social insurance transfer without affecting its tax price. The direct effect of a larger $\pi_{i}$ on $s_{i}^{*}$ is more difficult to ascertain. It hinges on how the expected marginal utility when old varies when agents put more relative weight on being dependent. We know from the decision not to buy private insurance that expected marginal utility if dependent is lower than first-period marginal utility. Saving then ensures that marginal utility in the first period is a convex combination of marginal utility if dependent and if not. We then obtain that 
marginal utility if autonomous is larger than if dependent, so that increasing $\pi_{i}$ actually decreases the expected marginal utility in second period, inducing the agent to save less. Observe that the indirect effects then reinforce the direct effects: a larger individual risk pushes directly the agent to insure more and save less, the latter reinforcing his incentive to insure more, while the former reinforces his incentive to save less.

We now consider the agents who most-prefer a positive amount of private insurance.

Proposition 3 Take the individuals with $\tau_{i}^{*}=0$ while $a_{i}^{*}>0$ (and $s_{i}^{*}>0$ ). We obtain that

(i) a larger income $w_{i}$ increases $s_{i}^{*}$ and has an ambiguous effect on $a_{i}^{*}$;

(ii) a larger family help (either $p_{i}$ or $f$ ) increases $s_{i}^{*}$ and decreases $a_{i}^{*}$;

(iii) a larger risk $\pi_{i}$ decreases $s_{i}^{*}$ and increases $a_{i}^{*}$.

Proof: Repeated use of Cramer's rule - see Appendix.

Agents with a larger income $w_{i}$ have a lower marginal utility from first-period consumption, which gives them more incentive to buy insurance and to save: the direct impact of $w_{i}$ on both $a_{i}^{*}$ and $s_{i}^{*}$ is positive. The indirect impact then goes into the opposite direction (since more saving induces to buy less insurance, while buying more insurance induces to save less). We show in the Appendix that the direct effect is unambiguously larger than the indirect one for saving, so that $s_{i}^{*}$ increases with $w_{i}$. As for insurance, the sign of the aggregate impact of $w_{i}$ depends on how saving affects the differential of second-period (expected) marginal utility according to dependency status. If more saving increases expected marginal utility when dependent compared to when autonomous, then richer agents buy more insurance. They buy less insurance in the opposite case. ${ }^{12}$

The sign of the impact of family help (as measured by either $f$ or $p_{i}$ ) on $a_{i}^{*}$ and $s_{i}^{*}$ is the same as on $\tau_{i}^{*}$ and $s_{i}^{*}$ as explained in Proposition 2, and the intuition is similar.

By contrast, the channels through which a higher individual risk $\pi_{i}$ impacts the most-preferred amount of private insurance and saving differ totally from the case studied in Proposition 2. Observe that, when $a_{i}^{*}>0$ and $s_{i}^{*}>0$, we have that $u^{\prime}\left(s_{i}\right)=u^{\prime}\left(c_{i}\right)=E H_{i}^{\prime}$, so that putting more relative weight on the dependency state does not affect the expected marginal utility when old. At the same time, increasing $\pi_{i}$ decreases the return from private insurance and thus lowers consumption levels (and increases marginal utility) when dependent. This direct impact of increasing $\pi_{i}$ then increases the willingness both to insure privately and to save. On the other hand, indirect effects have the opposite sign: the increase in incentives to save tend to decrease the incentive to buy private

\footnotetext{
${ }^{12}$ In the special case where $H(x)=u(x-z)$, we obtain that $d a_{i}^{*} / d w=0$.
} 
insurance, while the increase in incentives to insure tends to decrease the incentive to save. We obtain that the direct effect is larger than the indirect one for private insurance, while the opposite holds for saving. Intuitively, raising $\pi_{i}$ increases the expected marginal utility if dependent, and thus increases $a_{i}^{*}$. This in turn raises the marginal utility from first-period consumption, and pushes the individual to save less. In other words, a larger individual risk increases the expected marginal utility when dependent, and leads the individual to reallocate his portfolio in favor of private insurance and against saving.

We now put together the three propositions and summarize how individual characteristics affect separately the preferences for saving as well as social and private insurance, starting with income. Figure 1 shows the most-preferred levels of saving, social and private LTC insurance as functions of individual income. ${ }^{13}$ To facilitate the comparisons between the three schedules, we measure all three in terms of the amounts of transfer provided in the second period: $b\left(\tau_{i}^{*}\right)$ for social insurance, $x_{i}\left(a_{i}^{*}\right)$ for private insurance and $s_{i}^{*}$ for saving. An individual with a very low income most-favors a positive amount of social insurance, because he benefits from the income redistribution, but no private insurance. He also saves a positive amount. As income increases, $\tau_{i}^{*}$ decreases while $s_{i}^{*}$ increases. ${ }^{14}$ If this individual has a weak prospect of family help, the decline in $\tau_{i}^{*}$ as $w_{i}$ increases continues up to the point where $w_{i} / \pi_{i}=\bar{w} / \bar{\pi}$. At this point, the agent shifts his support from social to private insurance (i.e., $\tau_{i}^{*}=0$ while $\left.a_{i}^{*}>0\right) .{ }^{15}$ From that point on, any increase in $w_{i}$ has an ambiguous impact on $a_{i}^{*} \cdot{ }^{16}$ By continuity, $s_{i}^{*}$ increases with $w_{i}$ whether the agent prefers social or private insurance. If the agent rather enjoys a strong prospect of family help, his most-preferred value of $\tau_{i}^{*}$ reaches zero for a value of $w_{i}$ that is such that $w_{i} / \pi_{i}<\bar{w} / \bar{\pi}$. From that point on, the individual favors no insurance whatsoever. His preferred amount of saving increases with income in all cases.

\section{Insert Figure 1 here}

\footnotetext{
${ }^{13}$ Figures 1 to 3 are drawn under the assumptions that $u(x)=\log (x)$, that $H(x)=u(x-z)$ and, for Figures 1 and 2, that prospects of family help are weak. The analysis provided in the text is general and does not rely on such assumptions.

${ }^{14}$ Observe that this is true on Figure 1 even though the logarithmic utility function on which it is based does not satisfy Assumption 1. This illustrates that Assumption 1 is a sufficient although not necessary condition to obtain the comparative statics analysis described in Proposition 2 (i).

${ }^{15}$ More precisely, an agent with $w_{i} / \pi_{i}=\bar{w} / \bar{\pi}$ is indifferent between using private or social insurance, as long as the insurance transfer he receives when dependent corresponds to his optimal level.

${ }^{16}$ As stated in footnote 12 , with $H(x)=u(x-z), a_{i}^{*}>0$ is constant with $w_{i}$ : see Figure 1.
} 
We perform the same exercise for the individual risk. It will prove easier to treat separately the case of weak and strong family help prospects. With weak family help prospects (see Figure 2), agents with very low values of $\pi_{i}$ prefer some private insurance, ${ }^{17}$ with $a_{i}^{*}$ increasing with $\pi_{i}$. When $w_{i} / \pi_{i}=\bar{w} / \bar{\pi}$ is reached, they stop buying private insurance and rather switch to a strictly positive amount of social insurance. As $\pi_{i}$ further increases, $\tau_{i}^{*}$ increases as well. Saving $s_{i}^{*}$ decreases with $\pi_{i}$ whether $\tau_{i}^{*}>0$ (see Proposition 2) or $a_{i}^{*}>0$ (see Proposition 3). With strong family help prospects, agents never buy private insurance whatever their individual risk $\pi_{i}$. They most-prefer no social insurance as well, until their risk is large enough that $w_{i} / \pi_{i}$ is sufficiently small (and definitely smaller than $\bar{w} / \bar{\pi})$ that they gain enough from the ex ante redistribution across risk levels to favor $\tau_{i}^{*}>0$. From that point on, $\tau_{i}^{*}$ increases with $\pi_{i}$. Also, $s_{i}^{*}$ decreases with $\pi_{i}$ throughout with strong family help.

Insert Figure 2 here

We now turn to the impact of family help, as measured by $p_{i}$ (we obtain similar results when varying $f)$. Figure $3 \mathrm{~A}$ illustrates the results when $w_{i} / \pi_{i}<\bar{w} / \bar{\pi}$ while Figure 3B assumes that $w_{i} / \pi_{i}>\bar{w} / \bar{\pi}$. A very low value of $p_{i}$ means that the prospects of family help are weak for the individual. He then favors either $\tau_{i}^{*}>0$ if $w_{i} / \pi_{i}<\bar{w} / \bar{\pi}$ or $a_{i}^{*}>0$ if $w_{i} / \pi_{i}>\bar{w} / \bar{\pi}$. Increasing $p_{i}$ then decreases $\tau_{i}^{*}$ (Fig. 3A) or $a_{i}^{*}$ (Fig 3B), and increases $s_{i}^{*}$. If $w_{i} / \pi_{i}>\bar{w} / \bar{\pi}$, then $a_{i}^{*}$ converges to zero when $p_{i}$ is large enough that prospects of family help turn from weak to strong. ${ }^{18}$ If $w_{i} / \pi_{i}<\bar{w} / \bar{\pi}, \tau_{i}^{*}$ remains positive even for strong prospects of family help (thanks to income and risk redistribution), but decreases with $p_{i}$ until it becomes nil. When $p_{i}$ is large enough that $a_{i}^{*}=\tau_{i}^{*}=0$ (on either Fig. 3A or 3B), $s_{i}^{*}$ decreases with $p_{i}$ because a higher probability of family help decreases the expected marginal utility in the second period, and thus the expected benefit from saving. We then obtain that saving is not monotone in family help when agents endogenously switch from some (social or private) insurance to no insurance at all at their most-preferred allocation. ${ }^{19}$

\section{Insert Figures $3 \mathrm{~A}$ and $3 \mathrm{~B}$ here}

\footnotetext{
${ }^{17}$ This is reminiscent of the well known result (see Mossin (1968)) that risk-averse agents always wish to buy actuarially fair insurance.

${ }^{18}$ To cover all cases, we assume that $f$ is large enough that prospects of family help become strong when $p_{i}$ becomes large enough.

${ }^{19}$ As announced in the introduction, these results provide an analytical underpinning to those obtained by Costa-Font (2010): compare our Figures 3A and 3B with Costa-Font's Figure 6.
} 
To summarize, we obtain that having weak prospects of family help is a necessary condition to most-prefer a positive amount of private insurance. In that case, agents with large income and low individual risk buy private insurance. The most-preferred amount of private insurance increases with risk. On the other hand, low income and large risk individuals favor a larger social insurance program. In terms of crowding out effects, we then obtain that family support (as measured by either $f$ or $p_{i}$ ) decreases the support for both types of insurance. ${ }^{20}$ Such strong prospects for a large part of the polity may then explain the "puzzle" of the generalized lack of private insurance in OECD countries. Social insurance is less affected by family help thanks to the redistribution (across income and risk levels) that it entails. On a more prospective note, the decrease in family help that is widely expected to happen should give a boost to social and especially to private insurance, according to our model.

Before turning to the majority-chosen amount of social insurance, we should stress two limitations of the comparative static analysis we have performed. First, we have looked at variations of individual characteristics that affect a set of measure zero of individuals. This is of no import for family help, where the distribution of $p_{i}$ 's plays no role for individual preferences, so that the comparative static results we have obtained can be generalized when the characteristics of a set of positive measure of agents are changed. Unfortunately, we cannot proceed in the same way for variations of $w_{i}$ and $\pi_{i}$ for a group of agents when such variations affect $\bar{w}$ and $\bar{\pi}$, because of the role that average income and risk play in the government's budget balance equation (2). While we have shown that the individual impact of increasing $w_{i}$ on $\tau_{i}^{*}$ is negative, any increase in the income of a group of agents that raises the average income $\bar{w}$ would add another effect in the opposite direction since a larger tax base would increase the return of the social insurance scheme. Likewise, the individual impact of increasing $\pi_{i}$ on $\tau_{i}^{*}$ is positive, while an increase in $\pi_{i}$ for several agents that would raise $\bar{\pi}$ adds a countervailing force on $\tau_{i}^{*}$ by decreasing the return of the social insurance scheme.

The second limitation of Propositions 2 and 3 is that we assume that individual characteristics are modified one at a time (i.e., independently from one another). In reality, these individual characteristics are correlated. Observe that, if richer people tend to live longer and hence to have a larger probability of needing LTC (i.e., $\operatorname{cov}(w, \pi)>0$ ), then the net impact of a higher $w_{i}$ coupled with a higher

\footnotetext{
${ }^{20}$ When $p$ and $f$ are low enough that prospects of family help are weak, they crowd out the demand for social insurance by low $w_{i} / \pi_{i}$ types and for private insurance by large $w_{i} / \pi_{i}$ types. The crowding out is exclusively at the intensive margin, since the threshold value of $w_{i} / \pi_{i}$ (equal to $\bar{w} / \bar{\pi})$ which determines whether agents prefer social or private insurance is not affected by $f$ or $p$. When $p$ and $f$ are large enough that prospects of family help are strong, demand for private insurance disappears. From that point on, any increase in family help crowds out the demand for social insurance both at the intensive and at the extensive margins.
} 
$\pi_{i}$ on $s_{i}^{*}$ and $\tau_{i}^{*}$ is ambiguous. Whether one impact is larger than the other one is essentially an empirical matter of both the intensity of the correlation and the amount of variance in the two characteristics. For instance, if (as we surmise), the variance in income levels is larger than the variance in the risk levels (or if the covariance between both is low), then, under Assumption 1, richer people will favor a lower social insurance contribution rate (even though they may be riskier than poorer people).

Income may also be correlated with the probability of receiving family help, but the sign of the correlation is far from clear. Using macro data in Europe, one observes a negative correlation between income and family support, with richer Northern European countries providing less family help, on average, than poorer Southern countries (the so-called "North-South gradient", see SHARE (2005)). Focusing on micro data, Bonsang (2009) finds a positive correlation between income and family help. With a positive correlation, we obtain unambiguously that richer people prefer less social insurance, while the relationship between income and most-preferred social insurance can go both ways with a negative correlation between income and family support.

We now move to the majority-chosen level of social insurance.

\section{The majority-chosen level of social insurance}

Young agents vote first over $\tau$ and then choose $a$ and $s$. When assessing their preferences over $\tau$, we can make use of the envelope theorem for the choices of $a$ and $s$. Differentiating (3) with respect to $\tau$, it is straightforward to see that preferences over $\tau$ are concave (and thus single-peaked), so that we can apply the median voter theorem and obtain that there exists a value of $\tau$ that is preferred by a majority of voters to any other value of $\tau$. We denote this majority-chosen level of $\tau$ by $\tau^{V}$. It corresponds to the value of $\tau$ that is such that at least half the polity exhibits $\tau_{i}^{*} \geq \tau^{V}$ while at least half is such that $\tau_{i}^{*} \leq \tau^{V}$. Since individuals differ in three dimensions, it is not possible at this level of generality to define the characteristics of the decisive voters. But this will not prevent us from obtaining several interesting results.

First, observe that the set of agents who favor $\tau_{i}^{*}>0$ is made of all agents $i$ with $w_{i} / \pi_{i}<\bar{w} / \bar{\pi}$ and a weak prospect of family help together with all agents $i$ with a strong prospect of family help and a value of $w_{i} / \pi_{i}$ lower than some threshold that is itself strictly lower than $\bar{w} / \bar{\pi}$. If the mass of those two types of agents is at least equal to one half, then $\tau^{V}$ is strictly positive.

Second, from the discussion at the end of the previous section, we obtain that $\tau^{V}$ weakly decreases with family help. Unfortunately, as explained above, we can not draw similar inferences for variations in income and in risk. Also, 
it is impossible at this level of generality to assess the impact of modifying the correlation between, say, income and risk, or income and family help, on $\tau^{V}$.

In the introduction, we have mentioned that the literature has assessed how social insurance may decrease the demand for private insurance. Since several countries are currently considering how to facilitate access to private LTC insurance, we now study how the availability of private insurance impacts the support for social insurance. It is easy to see from the FOCs (3) and (4) that the two forms of insurance are imperfect substitutes. The intuition may then suggest that introducing the possibility to buy private insurance in a society where such insurance did not exist previously would always decrease the support for social insurance and result in a lower value of $\tau^{V}$. The next proposition shows that this need not be the case.

Proposition 4 If the proportion of individuals who face weak family prospects and are such that $w_{i} / \pi_{i}>\bar{w} / \bar{\pi}$ is lower than one half, then the introduction of the possibility to buy private insurance does not affect the majority-chosen value of the social insurance contribution rate, $\tau^{V}$.

The intuition for this proposition is that agents prefer either social or private insurance, but never both, so that introducing private insurance either does not change an individual's most-preferred value of $\tau$, or drives it to zero. Observe first that individuals who have strong prospects of family help never buy private insurance at their most-preferred allocation, so that introducing this form of insurance does not affect their preferences for social insurance. Among the agents who face weak prospects of family help, those with a ratio of income-to-risk lower than $\bar{w} / \bar{\pi}$ prefer social to private insurance, so that their most-preferred value of $\tau$ is not affected by the presence of private insurance. In other words, only agents facing weak prospects of family help and with a ratio of income-to-risk larger than $\bar{w} / \bar{\pi}$ react to the offering of private insurance by decreasing (to zero) their most-preferred amount of social insurance. Moreover, not all agents with a ratio $w_{i} / \pi_{i}$ larger than $\bar{w} / \bar{\pi}$ may prefer a strictly positive value of $\tau^{*}$ in the absence of private insurance (because agents with a very large value of $w_{i} / \pi_{i}$ may prefer to self-insure rather than buy into a social insurance program that heavily redistributes against them, as can be inferred from the FOC (6)). Hence, the condition detailed in Proposition 4 is sufficient but not necessary.

How likely is this sufficient condition to be satisfied? Observe that it is always empirically satisfied when agents do not differ in risk $\pi_{i}$. In that case, the crucial threshold is $\bar{w}$, and we know that $w_{m e d}<\bar{w}$ in all countries so that the condition is satisfied even if the prospects of family help are weak for all agents (see Figures $4 \mathrm{~A}$ and $4 \mathrm{~B}$ ). The sufficient condition will remain empirically valid if the variance of the income distribution is, as we surmise, much larger than the variance of the risk distribution. 
Insert Figures $4 \mathrm{~A}$ and $4 \mathrm{~B}$

\section{Conclusion}

This paper has studied the determinants of the demand for private, social and self-insurance for LTC in an environment where individuals differ in earnings, family support and dependence risk. We can use the results of our analysis to try and shed light on the future development of the three types of insurance for LTC. The two main changes expected to affect LTC in the near future are (i) the doubling in the number of dependent individuals in the next twenty years within the OECD, associated with the rapid increase of very old $(75+)$ people in the population, and (ii) the decline in family solidarity due to increased participation of women in the labor market, increased mobility and changing family values. The first effect can be modelled in our setting as an increase in the risk of becoming dependent of all agents. This higher risk will undoubtedly increase the needs when old, but we obtain that it does not necessarily imply an increase in the demand for social insurance, because a larger average risk of becoming dependent decreases the return of the social LTC insurance. Observe that the return of the (actuarially fair) private insurance decreases with the individual risk, while self-insurance return is not affected. The impact of a larger aggregate risk on the demand for social insurance thus depends on its distribution across people, and especially on its correlation with income. The impact of a diminishing family support is easier to ascertain: as we show, it unambiguously increases the demand for social insurance among agents with a low income-to-risk ratio. As for individuals with a high ratio, a decrease in family help will first increase their self-insurance level, and then increase their demand for private insurance.

Our paper introduces an admittedly crude modelling of family help, in that the amount of help is dictated by a social norm, with no distinction between formal and informal help. The next step in our research agenda is to lift those two constraints in order to better understand the demand for social and private LTC insurance as a function, for instance, of the substitutability/complementarity between formal and informal help (see Van Houtven and Norton, 2008).

\section{Appendix}

\section{Proof of Proposition 1}

(i) Observe from the FOC for $a_{i}$ that $a_{i}^{*}>0$ implies that $E H_{i}^{\prime}=u^{\prime}\left(c_{i}\right)$. This in turn implies that $F O C \tau_{i}>0$ if $w_{i} / \pi_{i}<\bar{w} / \bar{\pi}$, an impossibility, and that 
$F O C \tau_{i}<0$ if $w_{i} / \pi_{i}>\bar{w} / \bar{\pi}$, so that $\tau_{i}^{*}=0$. In the latter case, the FOC for saving implies that $E H_{i}^{\prime}=u^{\prime}\left(s_{i}\right)=u^{\prime}\left(c_{i}\right)$, which is compatible with the starting assumption that $a_{i}^{*}>0$.

Similarly, observe from the FOC for $\tau_{i}$ that $\tau_{i}^{*}>0$ implies that $E H_{i}^{\prime}=$ $\frac{w_{i}}{\pi_{i}} \frac{\bar{\pi}}{\bar{w}} u^{\prime}\left(c_{i}\right)$. If $w_{i} / \pi_{i}>\bar{w} / \bar{\pi}$, we then obtain that $E H_{i}^{\prime}>u^{\prime}\left(c_{i}\right)$ and so that $F O C a_{i}>0$, an impossibility. On the other hand, if $w_{i} / \pi_{i}<\bar{w} / \bar{\pi}$, we have that $E H_{i}^{\prime}<u^{\prime}\left(c_{i}\right)$ and that $F O C a_{i}<0$, implying that $a_{i}^{*}=0$. Finally, it is obvious that $w_{i} / \pi_{i}=\bar{w} / \bar{\pi}$ is indifferent between $a$ and $\tau$, provided that $E H_{i}^{\prime}=u^{\prime}\left(c_{i}\right)$-i.e., that they obtain their most-preferred total insurance amount.

(ii) We first show that people buy either private or social insurance with weak family help-i.e., that $a_{i}^{*}=\tau_{i}^{*}=0$ is impossible. In that case, with $a_{i}^{*}=\tau_{i}^{*}=0$, by the FOC for saving, we would have $E H_{i}^{\prime}>u^{\prime}\left(c_{i}\right)>u^{\prime}\left(s_{i}\right)$, which in turn would imply that $F O C a_{i}>0$, a contradiction with $a_{i}^{*}=0$. The proof of part (i) has then shown that we have $a_{i}^{*}>0$ and $\tau_{i}^{*}=0$ when $w_{i} / \pi_{i}>\bar{w} / \bar{\pi}$, and $a_{i}^{*}=0$ and $\tau_{i}^{*}>0$ when $w_{i} / \pi_{i}<\bar{w} / \bar{\pi}$.

(iii) With strong family help, when $a_{i}^{*}=\tau_{i}^{*}=0$, by the FOC for saving, we have $E H_{i}^{\prime} \leq u^{\prime}\left(c_{i}\right) \leq u^{\prime}\left(s_{i}\right)$, which in turn implies that $F O C a_{i} \leq 0$, consistent with $a_{i}^{*}=0$. We then have that $F O C \tau_{i} \leq 0$ for $\tau_{i}=0$ provided that $w_{i} / \pi_{i} \geq$ $x=(\bar{w} / \bar{\pi}) E H_{i}^{\prime} / u^{\prime}\left(c_{i}\right)$, with $x \leq \bar{w} / \bar{\pi}$ since $E H_{i}^{\prime} \leq u^{\prime}\left(c_{i}\right)$. If $w_{i} / \pi_{i}<x$, then we obtain that $F O C \tau_{i}>0$ at $\tau=0$, which is inconsistent with $\tau_{i}^{*}=0$. Observe that $E H_{i}^{\prime}$ decreases with $\tau_{i}$ while $u^{\prime}\left(c_{i}\right)$ increases with $\tau_{i}$. Take then the value of $\tau_{i}^{*}>0$ such that the FOC for $\tau$ equals zero. Observe that $E H_{i}^{\prime} \leq u^{\prime}\left(s_{i}\right)$ holds a fortiori when $\tau>0$ while prospects of family help are strong. Hence, from the FOC for saving, we still have that $E H_{i}^{\prime} \leq u^{\prime}\left(c_{i}\right) \leq u^{\prime}\left(s_{i}\right)$ and thus that the FOC for $a_{i}$ is negative: we have just shown that $\left(\tau_{i}^{*}>0, a_{i}^{*}=0\right)$ is consistent with the three FOCs. 
Proof of Proposition 2 (for the benefit of the referees, but could be deleted from the published article)

In that case, with $a_{i}^{*}=0$, the FOCs (3) and (5) simplify to

$$
\begin{aligned}
F O C \tau_{i} & :-w_{i} u^{\prime}\left(c_{i}\right)+\frac{\bar{w}}{\bar{\pi}} \pi_{i} E H_{i}^{\prime}=0 \\
F O C s_{i} & : \quad-u^{\prime}\left(c_{i}\right)+\left(1-\pi_{i}\right) u^{\prime}\left(s_{i}\right)+\pi_{i} E H_{i}^{\prime}=0
\end{aligned}
$$

where

$$
\begin{aligned}
c_{i} & =w_{i}\left(1-\tau_{i}\right)-s_{i} \text { and } \\
E H_{i}^{\prime} & =p_{i} H^{\prime}\left(s_{i}+\tau_{i} \frac{\bar{w}}{\bar{\pi}}+f\right)+\left(1-p_{i}\right) H^{\prime}\left(s_{i}+\tau_{i} \frac{\bar{w}}{\bar{\pi}}\right) .
\end{aligned}
$$

Straightforward application of the implicit function theorem on the system given by the FOCs (6) and (7) gives the following results.

(i)

$$
\frac{d \tau_{i}^{*}}{d w} \stackrel{s}{=} \frac{\partial F O C \tau_{i}}{\partial s_{i}} \frac{\partial F O C s_{i}}{\partial w_{i}}-\frac{\partial F O C \tau_{i}}{\partial w_{i}} \frac{\partial F O C s_{i}}{\partial s_{i}}<0
$$

since

$$
\begin{aligned}
& \frac{\partial F O C \tau_{i}}{\partial s_{i}}=w_{i} u^{\prime \prime}\left(c_{i}\right)+\frac{\bar{w}}{\bar{\pi}} \pi_{i} E H_{i}^{\prime \prime}<0, \\
& \frac{\partial F O C s_{i}}{\partial w_{i}}=-(1-\tau) u^{\prime \prime}\left(c_{i}\right)>0 \\
& \frac{\partial F O C \tau_{i}}{\partial w_{i}}=-u^{\prime}\left(c_{i}\right)-w_{i}(1-\tau) u^{\prime \prime}(c)<0 \text { under Assumption } 1, \\
& \frac{\partial F O C s_{i}}{\partial s_{i}}=u^{\prime \prime}\left(c_{i}\right)+\left(1-\pi_{i}\right) u^{\prime \prime}\left(s_{i}\right)+\pi_{i} E H_{i}^{\prime \prime}<0
\end{aligned}
$$

Likewise,

$$
\frac{d s_{i}^{*}}{d w} \stackrel{s}{=} \frac{\partial F O C s_{i}}{\partial \tau_{i}} \frac{\partial F O C \tau_{i}}{\partial w_{i}}-\frac{\partial F O C s_{i}}{\partial w_{i}} \frac{\partial F O C \tau_{i}}{\partial \tau_{i}}>0
$$

since

$$
\begin{aligned}
\frac{\partial F O C s_{i}}{\partial \tau_{i}} & =\frac{\partial F O C \tau_{i}}{\partial s_{i}}<0, \\
\frac{\partial F O C \tau_{i}}{\partial \tau_{i}} & =w_{i}^{2} u^{\prime \prime}\left(c_{i}\right)+\left(\frac{\bar{w}}{\bar{\pi}}\right)^{2} \pi_{i} E H_{i}^{\prime \prime}<0 .
\end{aligned}
$$

(ii)

$$
\frac{d \tau_{i}^{*}}{d p_{i}} \stackrel{s}{=} \frac{\partial F O C \tau_{i}}{\partial s_{i}} \frac{\partial F O C s_{i}}{\partial p_{i}}-\frac{\partial F O C \tau_{i}}{\partial p_{i}} \frac{\partial F O C s_{i}}{\partial s_{i}} \lessgtr 0,
$$


since

$$
\begin{aligned}
\frac{\partial F O C s_{i}}{\partial p_{i}} & =\pi_{i}\left[H_{i}^{\prime}\left(s_{i}+\tau_{i} \frac{\bar{w}}{\bar{\pi}}+f\right)-H_{i}^{\prime}\left(s_{i}+\tau_{i} \frac{\bar{w}}{\bar{\pi}}\right)\right]<0, \\
\frac{\partial F O C \tau_{i}}{\partial p_{i}} & =\frac{\bar{w}}{\bar{\pi}} \pi_{i}\left[H_{i}^{\prime}\left(s_{i}+\tau_{i} \frac{\bar{w}}{\bar{\pi}}+f\right)-H_{i}^{\prime}\left(s_{i}+\tau_{i} \frac{\bar{w}}{\bar{\pi}}\right)\right]<0 .
\end{aligned}
$$

Using the fact that

$$
\frac{\partial F O C \tau_{i}}{\partial p_{i}}=\frac{\bar{w}}{\bar{\pi}} \frac{\partial F O C s_{i}}{\partial p_{i}}
$$

we obtain

$$
\begin{aligned}
\frac{d \tau_{i}^{*}}{d p_{i}} \quad & \stackrel{s}{=} \frac{\partial F O C s_{i}}{\partial p_{i}}\left[\frac{\partial F O C \tau_{i}}{\partial s_{i}}-\frac{\bar{w}}{\bar{\pi}} \frac{\partial F O C s_{i}}{\partial s_{i}}\right] \\
= & \frac{\partial F O C s_{i}}{\partial p_{i}}\left[u^{\prime \prime}\left(c_{i}\right)\left(w-\frac{\bar{w}}{\bar{\pi}}\right)-\frac{\bar{w}}{\bar{\pi}}\left(1-\pi_{i}\right) u^{\prime \prime}\left(s_{i}\right)\right]<0,
\end{aligned}
$$

since $\frac{w}{\pi}<\frac{\bar{w}}{\bar{\pi}}$.

Likewise,

$$
\frac{d s_{i}^{*}}{d p_{i}} \stackrel{s}{=} \frac{\partial F O C s_{i}}{\partial \tau_{i}} \frac{\partial F O C \tau_{i}}{\partial p_{i}}-\frac{\partial F O C s_{i}}{\partial p_{i}} \frac{\partial F O C \tau_{i}}{\partial \tau_{i}} \lessgtr 0 .
$$

Using the fact that

$$
\frac{\partial F O C \tau_{i}}{\partial p_{i}}=\frac{\bar{w}}{\bar{\pi}} \frac{\partial F O C s_{i}}{\partial p_{i}}
$$

we obtain

$$
\begin{aligned}
\frac{d s_{i}^{*}}{d p_{i}} \quad & \stackrel{s}{=} \frac{\partial F O C s_{i}}{\partial p_{i}}\left[\frac{\bar{w}}{\bar{\pi}} \frac{\partial F O C s_{i}}{\partial \tau_{i}}-\frac{\partial F O C \tau_{i}}{\partial \tau_{i}}\right] \\
= & \frac{\partial F O C s_{i}}{\partial p_{i}}\left[u^{\prime \prime}\left(c_{i}\right)\left(\frac{\bar{w}}{\bar{\pi}} w_{i}-\left(w_{i}\right)^{2}\right)\right]>0
\end{aligned}
$$

since $w<\frac{w}{\pi}<\frac{\bar{w}}{\bar{\pi}}$.

Also, we have that

$$
\frac{d \tau_{i}^{*}}{d d} \stackrel{s}{=} \frac{\partial F O C \tau_{i}}{\partial s_{i}} \frac{\partial F O C s_{i}}{\partial f}-\frac{\partial F O C \tau_{i}}{\partial f} \frac{\partial F O C s_{i}}{\partial s_{i}},
$$

with

$$
\begin{aligned}
\frac{\partial F O C s_{i}}{\partial f} & =\pi_{i} p_{i} H_{i}^{\prime \prime}\left(s_{i}+\tau \frac{\bar{w}}{\bar{\pi}}+f\right)<0, \\
\frac{\partial F O C \tau_{i}}{\partial f} & =\frac{\bar{w}}{\bar{\pi}} \pi_{i} p_{i} H_{i}^{\prime \prime}\left(s_{i}+\tau \frac{\bar{w}}{\bar{\pi}}+f\right)<0 .
\end{aligned}
$$


Using the fact that

$$
\frac{\partial F O C \tau_{i}}{\partial f}=\frac{\bar{w}}{\bar{\pi}} \frac{\partial F O C s_{i}}{\partial f}
$$

we obtain

$$
\frac{d \tau_{i}^{*}}{d d} \stackrel{s}{=} \frac{\partial F O C s_{i}}{\partial f}\left[\frac{\partial F O C \tau_{i}}{\partial s_{i}}-\frac{\bar{w}}{\bar{\pi}} \frac{\partial F O C s_{i}}{\partial s_{i}}\right]<0
$$

Likewise,

$$
\frac{d s_{i}^{*}}{d d} \stackrel{s}{=} \frac{\partial F O C s_{i}}{\partial \tau_{i}} \frac{\partial F O C \tau_{i}}{\partial f}-\frac{\partial F O C s_{i}}{\partial f} \frac{\partial F O C \tau_{i}}{\partial \tau_{i}} \lessgtr 0 .
$$

Using the fact that

$$
\frac{\partial F O C \tau_{i}}{\partial f}=\frac{\bar{w}}{\bar{\pi}} \frac{\partial F O C s_{i}}{\partial f}
$$

we obtain

$$
\frac{d s_{i}^{*}}{d d} \stackrel{s}{=} \frac{\partial F O C s_{i}}{\partial f}\left[\frac{\bar{w}}{\bar{\pi}} \frac{\partial F O C s_{i}}{\partial \tau_{i}}-\frac{\partial F O C \tau_{i}}{\partial \tau_{i}}\right]>0
$$

(iii)

$$
\frac{d \tau_{i}^{*}}{d \Pi_{i}} \stackrel{s}{=} \frac{\partial F O C \tau_{i}}{\partial s_{i}} \frac{\partial F O C s_{i}}{\partial \pi_{i}}-\frac{\partial F O C \tau_{i}}{\partial \pi_{i}} \frac{\partial F O C s_{i}}{\partial s_{i}}>0
$$

since

$$
\begin{aligned}
\frac{\partial F O C \tau_{i}}{\partial \pi_{i}} & =\frac{\bar{w}}{\bar{\pi}} E H_{i}^{\prime}>0, \\
\frac{\partial F O C s_{i}}{\partial \pi_{i}} & =E H_{i}^{\prime}-u^{\prime}\left(s_{i}\right)<0,
\end{aligned}
$$

where, to sign the latter, we make use of the fact that $a_{i}^{*}<0$, which implies that $E H_{i}^{\prime}<u^{\prime}\left(c_{i}\right)$, and by the FOC for saving that $E H_{i}^{\prime}<u^{\prime}\left(c_{i}\right)<u^{\prime}\left(s_{i}\right)$.

Likewise, we obtain that

$$
\frac{d s_{i}^{*}}{d \Pi_{i}} \stackrel{s}{=} \frac{\partial F O C s_{i}}{\partial \tau_{i}} \frac{\partial F O C \tau_{i}}{\partial \pi_{i}}-\frac{\partial F O C s_{i}}{\partial \pi_{i}} \frac{\partial F O C \tau_{i}}{\partial \tau_{i}}<0 .
$$

Proof of Proposition 3 (could be deleted from published article as well)

In that case, with $\tau_{i}^{*}=0$, the FOCs (4) and (5) simplify to

$$
\begin{aligned}
F O C a_{i}: & -u^{\prime}\left(c_{i}\right)+E H_{i}^{\prime}=0 \\
F O C s_{i}: & -u^{\prime}\left(c_{i}\right)+\left(1-\pi_{i}\right) u^{\prime}\left(s_{i}\right)+\pi_{i} E H_{i}^{\prime}=0,
\end{aligned}
$$


where

$$
\begin{aligned}
c_{i} & =w_{i}-s_{i}-a_{i} \text { and } \\
E H_{i}^{\prime} & =p_{i} H^{\prime}\left(s_{i}+\frac{a_{i}}{\pi_{i}}+f\right)+\left(1-p_{i}\right) H^{\prime}\left(s_{i}+\frac{a_{i}}{\pi_{i}}\right) .
\end{aligned}
$$

Straightforward application of the implicit function theorem on the system given by the FOCs (8) and (9) gives the following results.

(i)

$$
\frac{d a_{i}^{*}}{d w} \stackrel{s}{=} \frac{\partial F O C a_{i}}{\partial s_{i}} \frac{\partial F O C s_{i}}{\partial w_{i}}-\frac{\partial F O C a_{i}}{\partial w_{i}} \frac{\partial F O C s_{i}}{\partial s_{i}} \lessgtr 0,
$$

since

$$
\begin{aligned}
& \frac{\partial F O C a_{i}}{\partial s_{i}}=u^{\prime \prime}\left(c_{i}\right)+E H_{i}^{\prime \prime}<0, \\
& \frac{\partial F O C s_{i}}{\partial w_{i}}=-u^{\prime \prime}\left(c_{i}\right)>0, \\
& \frac{\partial F O C a_{i}}{\partial w_{i}}=-u^{\prime}\left(c_{i}\right)>0, \\
& \frac{\partial F O C s_{i}}{\partial s_{i}}=u^{\prime \prime}\left(c_{i}\right)+\left(1-\pi_{i}\right) u^{\prime \prime}\left(s_{i}\right)+\pi_{i} E H_{i}^{\prime \prime}<0 .
\end{aligned}
$$

Using the fact that

$$
\frac{\partial F O C a_{i}}{\partial w_{i}}=\frac{\partial F O C s_{i}}{\partial w_{i}}
$$

we obtain

$$
\begin{aligned}
\frac{d a_{i}^{*}}{d w_{i}} \quad & \stackrel{s}{=} \frac{\partial F O C a_{i}}{\partial w_{i}}\left[\frac{\partial F O C a_{i}}{\partial s_{i}}-\frac{\partial F O C s_{i}}{\partial s_{i}}\right] \\
= & \frac{\partial F O C a_{i}}{\partial w_{i}}\left[\left(1-\pi_{i}\right)\left(E H_{i}^{\prime \prime}-u^{\prime \prime}\left(s_{i}\right)\right)\right] \lessgtr 0 .
\end{aligned}
$$

Likewise,

$$
\frac{d s_{i}^{*}}{d w} \stackrel{s}{=} \frac{\partial F O C s_{i}}{\partial a_{i}} \frac{\partial F O C a_{i}}{\partial w_{i}}-\frac{\partial F O C s_{i}}{\partial w_{i}} \frac{\partial F O C a_{i}}{\partial a_{i}} \lessgtr 0,
$$

since

$$
\begin{aligned}
\frac{\partial F O C s_{i}}{\partial a_{i}} & =\frac{\partial F O C a_{i}}{\partial s_{i}}<0 \\
\frac{\partial F O C a_{i}}{\partial a_{i}} & =u^{\prime \prime}\left(c_{i}\right)+\frac{E H_{i}^{\prime \prime}}{\pi_{i}}<0
\end{aligned}
$$


Using the fact that

$$
\frac{\partial F O C a_{i}}{\partial w_{i}}=\frac{\partial F O C s_{i}}{\partial w_{i}}
$$

we obtain

$$
\begin{aligned}
\frac{d s_{i}^{*}}{d w_{i}} & \stackrel{s}{=} \frac{\partial F O C a_{i}}{\partial w_{i}}\left[\frac{\partial F O C s_{i}}{\partial a_{i}}-\frac{\partial F O C a_{i}}{\partial a_{i}}\right] \\
= & \frac{\partial F O C a_{i}}{\partial w_{i}}\left[\left(1-\frac{1}{\pi_{i}}\right) E H_{i}^{\prime \prime}\right]>0 .
\end{aligned}
$$

(ii)

$$
\frac{d a_{i}^{*}}{d p_{i}} \stackrel{s}{=} \frac{\partial F O C a_{i}}{\partial s_{i}} \frac{\partial F O C s_{i}}{\partial p_{i}}-\frac{\partial F O C a_{i}}{\partial p_{i}} \frac{\partial F O C s_{i}}{\partial s_{i}} \lessgtr 0,
$$

since

$$
\begin{aligned}
& \frac{\partial F O C s_{i}}{\partial p_{i}}=\pi_{i}\left[H_{i}^{\prime}\left(s_{i}+\frac{a_{i}}{\pi_{i}}+f\right)-H_{i}^{\prime}\left(s_{i}+\frac{a_{i}}{\pi_{i}}\right)\right]<0, \\
& \frac{\partial F O C a_{i}}{\partial p_{i}}=H_{i}^{\prime}\left(s_{i}+\frac{a_{i}}{\pi_{i}}+f\right)-H_{i}^{\prime}\left(s_{i}+\frac{a_{i}}{\pi_{i}}\right)<0 .
\end{aligned}
$$

Using the fact that

$$
\frac{\partial F O C s_{i}}{\partial p_{i}}=\pi_{i} \frac{\partial F O C a_{i}}{\partial p_{i}}
$$

we obtain

$$
\begin{aligned}
\frac{d a_{i}^{*}}{d p_{i}} \quad & \stackrel{s}{=} \frac{\partial F O C a_{i}}{\partial p_{i}}\left[\pi_{i} \frac{\partial F O C a_{i}}{\partial s_{i}}-\frac{\partial F O C s_{i}}{\partial s_{i}}\right] \\
= & -\frac{\partial F O C a_{i}}{\partial p_{i}}\left[\left(1-\pi_{i}\right)\left(u^{\prime \prime}\left(c_{i}\right)+u^{\prime \prime}\left(s_{i}\right)\right)\right]<0 .
\end{aligned}
$$

Likewise,

$$
\frac{d s_{i}^{*}}{d p_{i}} \stackrel{s}{=} \frac{\partial F O C s_{i}}{\partial a_{i}} \frac{\partial F O C a_{i}}{\partial p_{i}}-\frac{\partial F O C s_{i}}{\partial p_{i}} \frac{\partial F O C a_{i}}{\partial a_{i}} \lessgtr 0 .
$$

Using the fact that

$$
\frac{\partial F O C s_{i}}{\partial p_{i}}=\pi_{i} \frac{\partial F O C a_{i}}{\partial p_{i}}
$$

we obtain

$$
\begin{aligned}
\frac{d s_{i}^{*}}{d p_{i}} & \quad \stackrel{s}{=} \frac{\partial F O C a_{i}}{\partial p_{i}}\left[\frac{\partial F O C s_{i}}{\partial a_{i}}-\pi_{i} \frac{\partial F O C a_{i}}{\partial a_{i}}\right] \\
= & \frac{\partial F O C a_{i}}{\partial p_{i}}\left[\left(1-\pi_{i}\right) u^{\prime \prime}\left(c_{i}\right)\right]>0 .
\end{aligned}
$$


Also, we have that

$$
\frac{d a_{i}^{*}}{d d} \stackrel{s}{=} \frac{\partial F O C a_{i}}{\partial s_{i}} \frac{\partial F O C s_{i}}{\partial f}-\frac{\partial F O C a_{i}}{\partial f} \frac{\partial F O C s_{i}}{\partial s_{i}} \lessgtr 0,
$$

since

$$
\begin{aligned}
& \frac{\partial F O C s_{i}}{\partial f}=\pi_{i} p_{i} H_{i}^{\prime \prime}\left(s_{i}+\frac{a_{i}}{\pi_{i}}+f\right)<0, \\
& \frac{\partial F O C a_{i}}{\partial f}=p_{i} H_{i}^{\prime \prime}\left(s_{i}+\frac{a_{i}}{\pi_{i}}+f\right)<0 .
\end{aligned}
$$

Using the fact that

$$
\frac{\partial F O C s_{i}}{\partial f}=\pi_{i} \frac{\partial F O C a_{i}}{\partial f}
$$

we obtain

$$
\frac{d a_{i}^{*}}{d d} \stackrel{s}{=} \frac{\partial F O C a_{i}}{\partial f}\left[\pi_{i} \frac{\partial F O C a_{i}}{\partial s_{i}}-\frac{\partial F O C s_{i}}{\partial s_{i}}\right]<0 .
$$

Likewise,

$$
\frac{d s_{i}^{*}}{d d} \stackrel{s}{=} \frac{\partial F O C s_{i}}{\partial a_{i}} \frac{\partial F O C a_{i}}{\partial f}-\frac{\partial F O C s_{i}}{\partial f} \frac{\partial F O C a_{i}}{\partial a_{i}} \lessgtr 0 .
$$

Using the fact that

$$
\frac{\partial F O C s_{i}}{\partial f}=\pi_{i} \frac{\partial F O C a_{i}}{\partial f}
$$

we obtain

$$
\frac{d s_{i}^{*}}{d d} \stackrel{s}{=} \frac{\partial F O C a_{i}}{\partial f}\left[\frac{\partial F O C s_{i}}{\partial a_{i}}-\pi_{i} \frac{\partial F O C a_{i}}{\partial a_{i}}\right]>0
$$

(iii)

$$
\frac{d a_{i}^{*}}{d \Pi_{i}} \stackrel{s}{=} \frac{\partial F O C a_{i}}{\partial s_{i}} \frac{\partial F O C s_{i}}{\partial \pi_{i}}-\frac{\partial F O C a_{i}}{\partial \pi_{i}} \frac{\partial F O C s_{i}}{\partial s_{i}} \lessgtr 0,
$$

since

$$
\begin{aligned}
& \frac{\partial F O C a_{i}}{\partial \pi_{i}}=-\frac{a_{i} E H_{i}^{\prime \prime}}{\pi_{i}}>0, \\
& \frac{\partial F O C s_{i}}{\partial \pi_{i}}=E H_{i}^{\prime}-u^{\prime}\left(s_{i}\right)-\pi_{i} \frac{a_{i} E H_{i}^{\prime \prime}}{\pi_{i}}=-\frac{a_{i} E H_{i}^{\prime \prime}}{\pi_{i}}>0,
\end{aligned}
$$

since $E H_{i}^{\prime}=u^{\prime}\left(s_{i}\right)$ when $a_{i}^{*}>0$ and $s_{i}^{*}>0$. Using the fact that

$$
\frac{\partial F O C s_{i}}{\partial \pi_{i}}=\pi_{i} \frac{\partial F O C a_{i}}{\partial \pi_{i}},
$$


we obtain

$$
\frac{d a_{i}^{*}}{d \Pi_{i}} \stackrel{s}{=} \frac{\partial F O C a_{i}}{\partial \pi_{i}}\left[\pi_{i} \frac{\partial F O C a_{i}}{\partial s_{i}}-\frac{\partial F O C s_{i}}{\partial s_{i}}\right]>0
$$

Likewise,

$$
\frac{d s_{i}^{*}}{d \Pi_{i}} \stackrel{s}{=} \frac{\partial F O C s_{i}}{\partial a_{i}} \frac{\partial F O C a_{i}}{\partial \pi_{i}}-\frac{\partial F O C s_{i}}{\partial \pi_{i}} \frac{\partial F O C a_{i}}{\partial a_{i}} \lessgtr 0 .
$$

Using the fact that

$$
\frac{\partial F O C s_{i}}{\partial \pi_{i}}=\pi_{i} \frac{\partial F O C a_{i}}{\partial \pi_{i}}
$$

we obtain

$$
\frac{d s_{i}^{*}}{d \Pi_{i}} \stackrel{s}{=} \frac{\partial F O C a_{i}}{\partial \pi_{i}}\left[\frac{\partial F O C s_{i}}{\partial a_{i}}-\pi_{i} \frac{\partial F O C a_{i}}{\partial a_{i}}\right]<0
$$

\section{References}

[1] Bonsang, E., (2009), Does informal care from children to their elderly parents substitute for formal care in Europe?, Journal of Health Economics, 28, 143154 .

[2] Brown, J., and A. Finkelstein, (2007), Why is the Market for Long-term Care Insurance so Small,Journal of Public Economics, 91(10), 1967-91.

[3] Casamatta, G., H. Cremer and P. Pestieau, (2000), The political economy of social security, Scandinavian Journal of Economics, 102, 503-522.

[4] Costa-Font, J., (2010), Family ties and the crowding out of long-term care insurance, Oxford Review of Economic Policy, 26 (4), 691-712.

[5] Courbage, C. and N. Roudaut, (2008), Empirical evidence of long-term care insurance purchase in France, The Geneva Papers on Risk and Insurance Issues and Practice, 33(4), 645-656.

[6] Courbage, C., and P. Zweifel, (2011), Two-sided intergenerational moral hazard, long-term care insurance, and nursing home use", Journal of Risk and Uncertainty, 43(1), 65-80.

[7] Cremer, H., Ph. De Donder and P. Pestieau, (2009), Providing sustainable long term care: a looming challenge, Toulouse School of Economics Notes, $\mathrm{n}^{\circ} 3$, available at http://www.tsefr.eu/images/TSE/TSENotes/tsenotes3.pdf 
[8] Cremer, H. and P. Pestieau, (2013), Long term care social insurance and redistribution, International Journal of Tax and Public Finance, forthcoming.

[9] De Donder, Ph. and M.-L. Leroux, (2013), Behavioral Biases and Long Term Care Annuities: A Political Economy Approach, The B.E. Journal of Economic Analysis \& Policy (Advances), forthcoming.

[10] Fabel, O., (1996), Institutional change, the demand for long-term care insurance and savings, FinanzArchiv, 53, 582-605.

[11] Finkelstein, A., Luttmer, E., and M. Notowidigdo, (2009), Approaches to estimating the health state dependence of the utility function, American Economic Review, 99(2), 116-121.

[12] Finkelstein, A., E. Luttmer, and M. Notowidigdo, (2013), What good is wealth without health? The effect of health on the marginal utility of consumption, Journal of the European Economic Association 11:221-58.

[13] Halek, M and JG Eisenhauer, (2001), Demography of Risk Aversion, Journal of Risk and Insurance, 68(1): 1-24.

[14] Hansen, LP and KJ Singleton, (1983), Stochastic Consumption, Risk Aversion, and the Temporal Behavior of Asset Returns, Journal of Political Economy, 91(2): 249-265.

[15] Holt, CA and SK Laury, (2002), Risk Aversion and Incentive Effects, American Economic Review, 92(5): 1644-1655.

[16] Karagyozova, T., and P. Siegelman, (2012), Can propitious selection stabilize insurance markets ?, Journal of Insurance Issues 35 (2): 121-158.

[17] Meier, V., (1996), Long-term care insurance and savings, FinanzArchiv, 53, 561-581.

[18] Mellor, J.M., (2001), Long-term care and nursing home coverage: are adult children substitutes for insurance policies?, Journal of Health Economics, $20(4), 527-547$.

[19] Mossin, (1968), Aspects of rational insurance purchasing, Journal of Political Economy, 76, p. 533-568.

[20] Norton, E. C., (1995), Elderly Assets, Medicaid Policy, and Spend-down in Nursing Homes, Review of Income and Wealth, 41(3), 309-29. 
[21] Nuscheler, R. and K. Roeder, (2013), The political economy of long term care, European Economic Review 62: 154-173.

[22] Pauly, M.V., (1990), The rational non-purchase of long-term care insurance, Journal of Political Economy, 95, 153-68.

[23] SHARE (2005), Health, Ageing and Retirement in Europe. First Results from the Survey of Health, Ageing and Retirement in Europe.

[24] Stone, R. (2000), Long-Term Care for the Elderly with Disabilities: Current Policy, Emerging Trends, and Implications for the Twenty-First Century, Milbank Memorial Fund. Available at http://www.milbank.org/reports/0008stone/LongTermCare_Mech5.pdf

[25] Van Houtven, C., and E. Norton, (2008), Informal care and Medicare expenditures: Testing for heterogeneous treatment effects, Journal of Health Economics, 27, 134-156.

[26] Zweifel, P., and W. Strüwe, (1996), Long-term care insurance and bequests as instruments for shaping intergenerational relationships, Journal of Risk and Uncertainty, 12, 65-76.

[27] Zweifel, P., and W. Strüwe, (1998), Long-term care insurance in a two generation model, Journal of Risk and Insurance, 65, 33-56. 


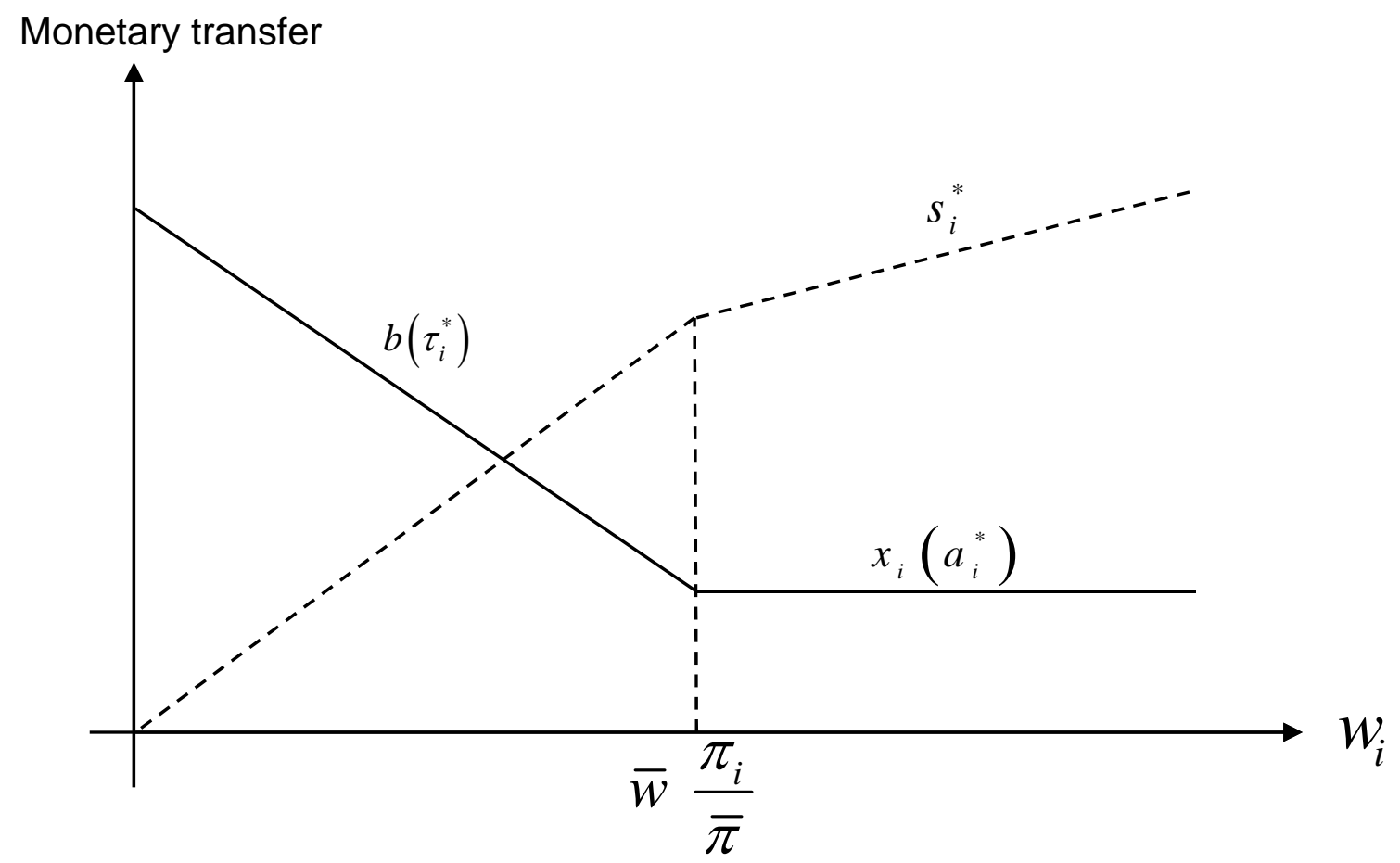

Figure 1 : Social, private and self-insurance transfers as functions of $w_{i}$ with weak prospect of family help, logarithmic utility and $\mathrm{H}(x)=u(x-z)$

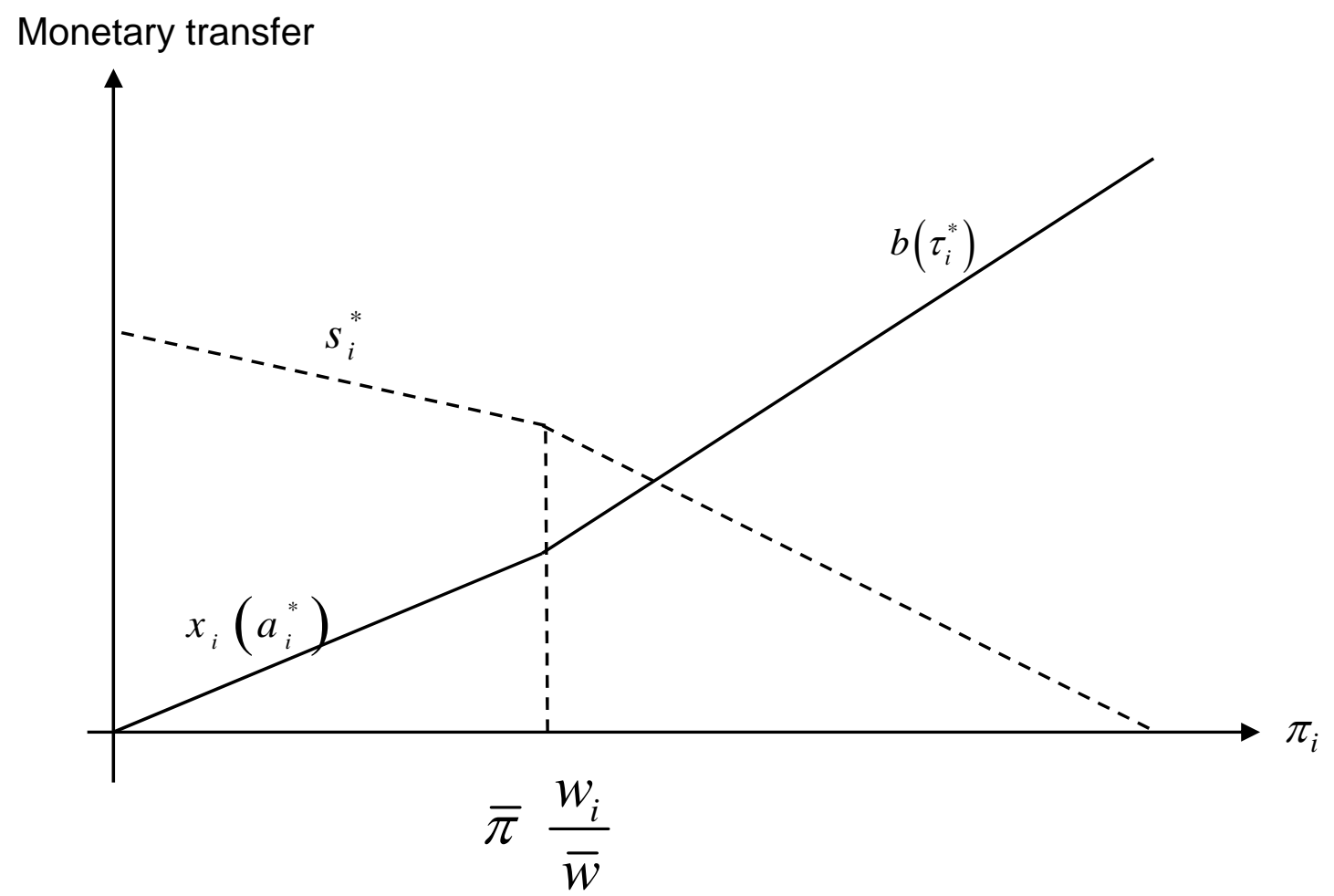

Figure 2 : Social, private and self-insurance transfers as functions of $w_{i}$ with weak prospect of family help, logarithmic utility and $\mathrm{H}(x)=u(x-z)$ 
Monetary transfer

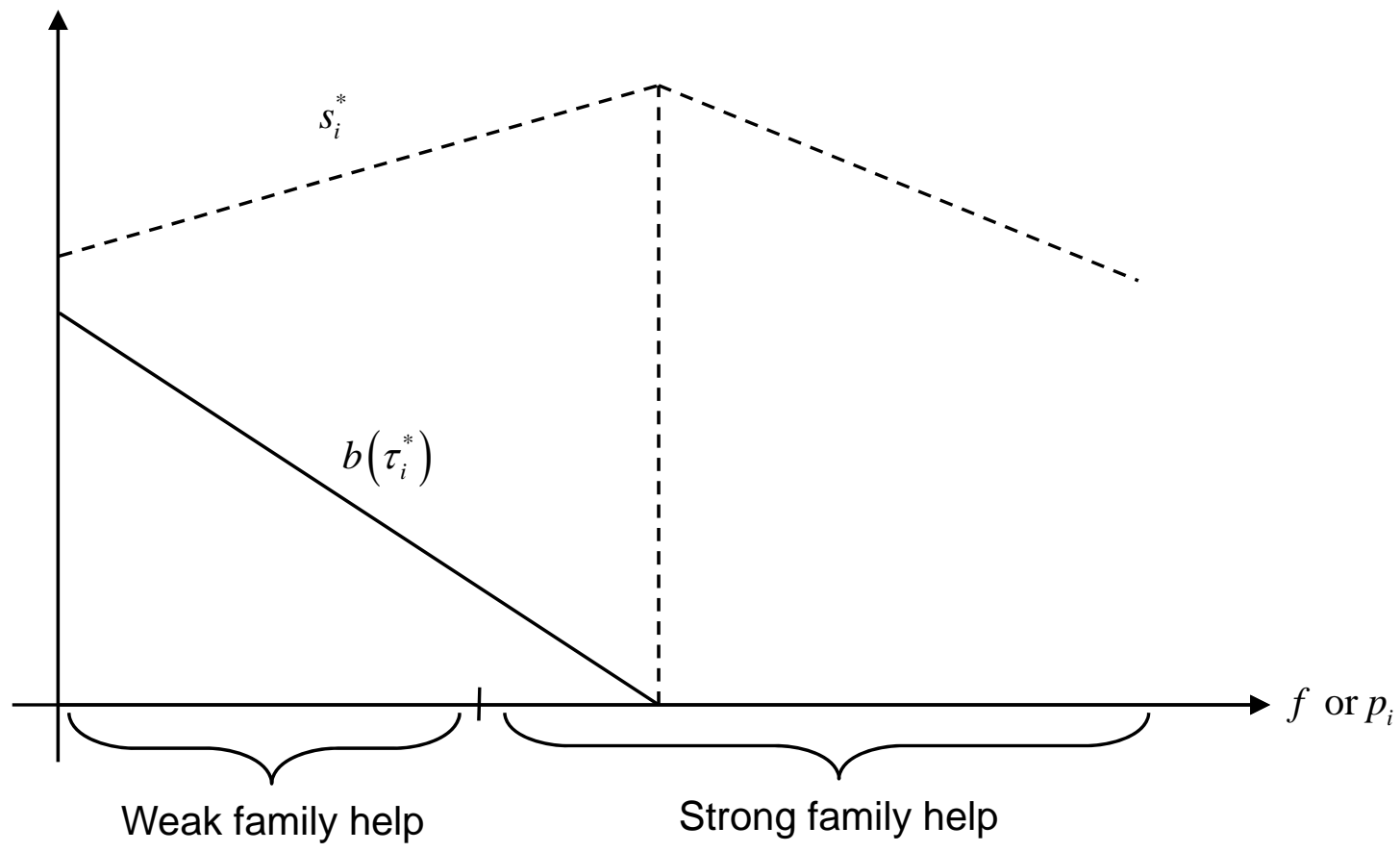

Figure $3 \mathrm{~A}$ : Social and self-insurance transfers as a function of $f$ or $p_{i}$ with $\frac{w_{i}}{\pi_{i}}<\frac{\bar{w}}{\bar{\pi}}$, logarithmic utility and $\mathrm{H}(x)=u(x-z)$

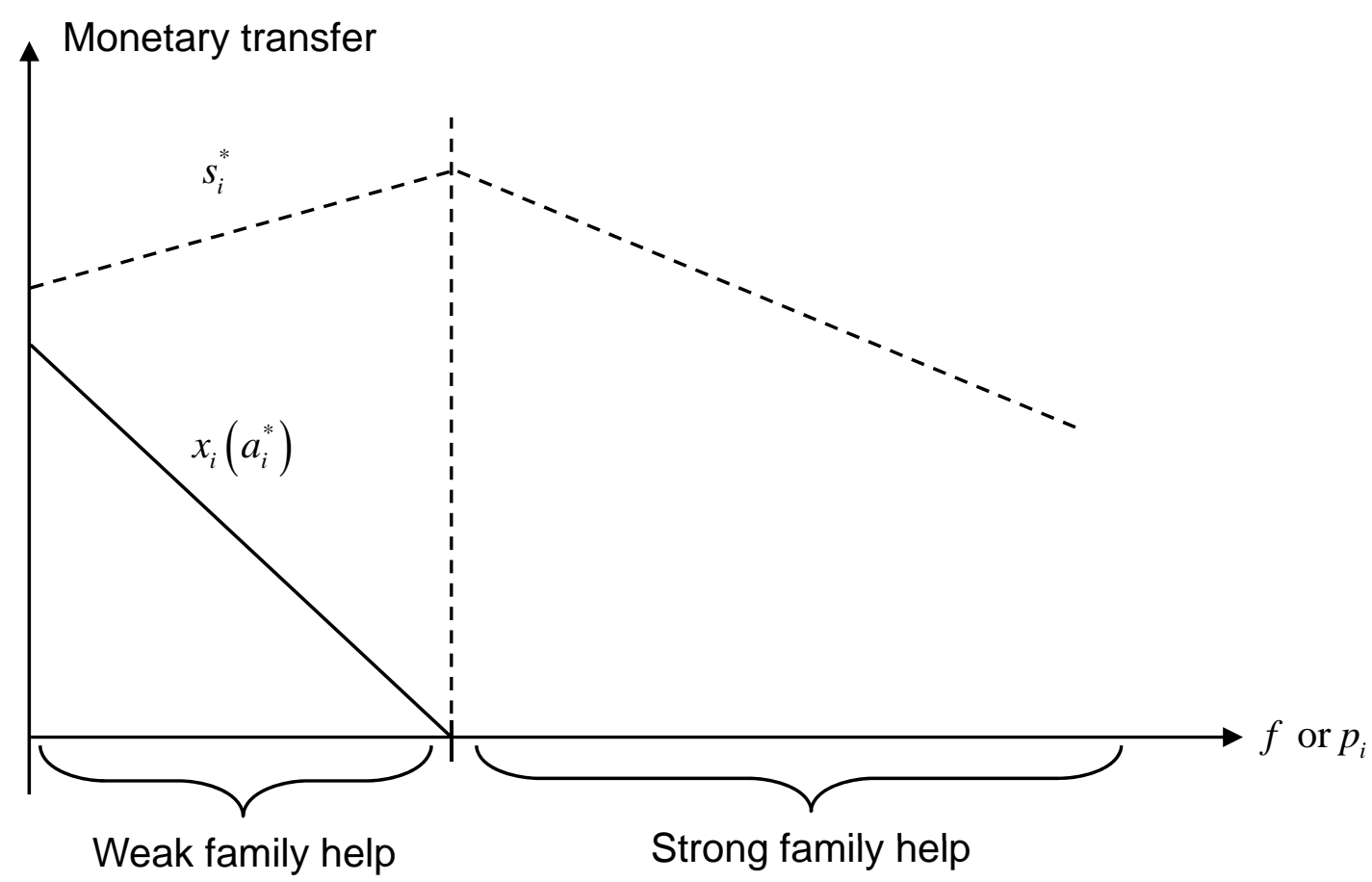

Figure $3 \underset{W}{\mathrm{~B}}$ : Private and self-insurance transfers as a function of $f$ or $p_{i}$ with $\frac{w_{i}}{\pi_{i}}>\frac{\bar{w}}{\bar{\pi}}$, logarithmic utility and $\mathrm{H}(x)=u(x-z)$ 


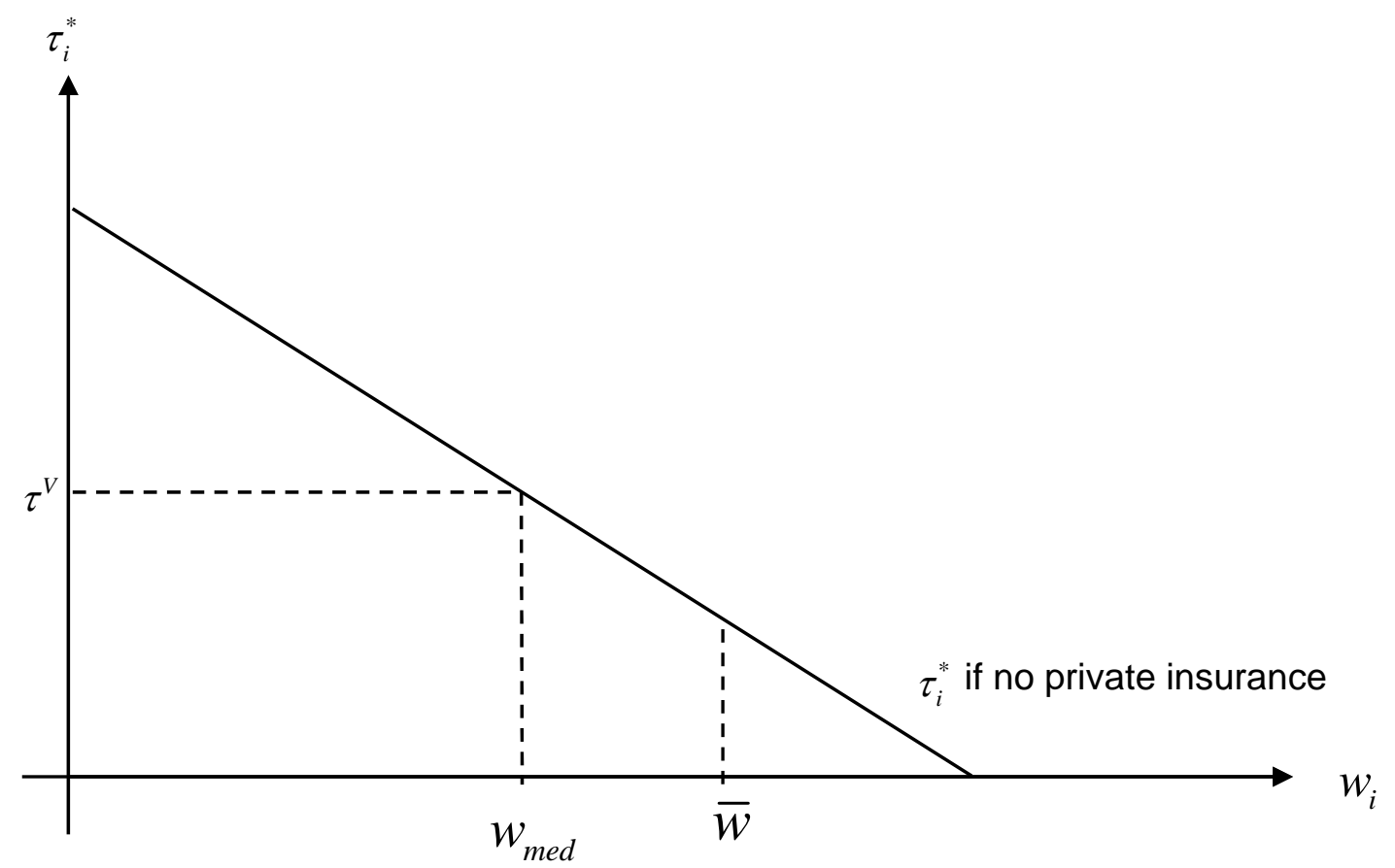

Figure 4A : Majority-chosen value of $\tau_{i}^{*}$ without private insurance when agents differ only in income 


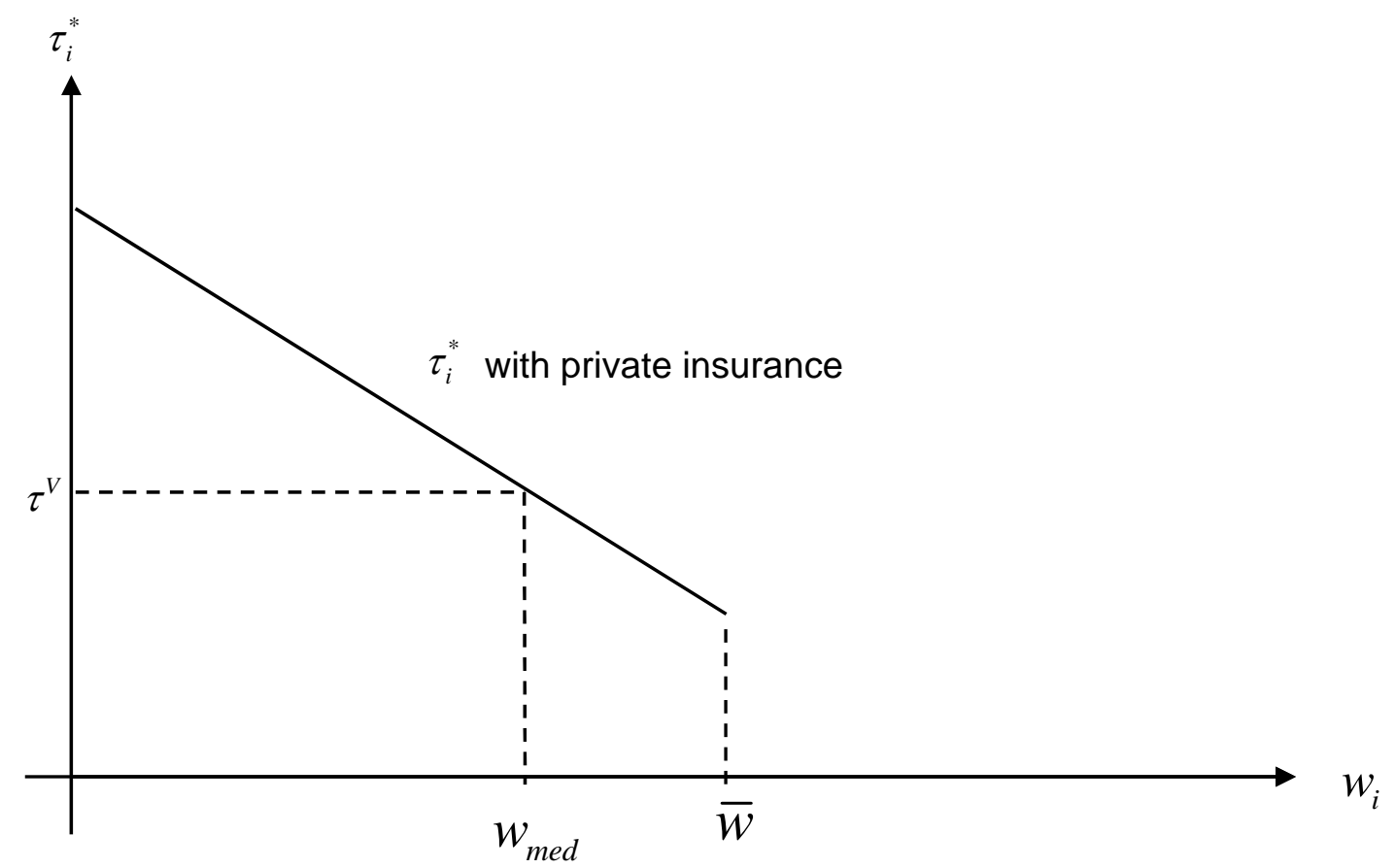

Figure 4B : Majority-chosen value of $\tau_{i}^{*}$ with private insurance when agents differ only in income 